\title{
Heterogeneity of Sentiment Risk in Malaysian Stock Market
}

\author{
Jasman Tuyon $^{1}$, Zamri Ahmad ${ }^{2}$, Mohd Fahmi Ghazali ${ }^{3}$ \\ Faculty of Business Management, Universiti Teknologi MARA, Sabah ${ }^{1}$ \\ School of Management, Universiti Sains Malaysia ${ }^{2}$ \\ Labuan Faculty of International Finance, Universiti Malaysia Sabah ${ }^{3}$
}

\begin{abstract}
Behavioral risks including investor sentiment play an important role in Asia's stock market behaviors, but they are theoretically and empirically not well understood in traditional conditional means statistics, partly due to the heterogeneity roles. In contrast to the existing studies, this paper examines the heterogeneity roles of investor sentiment proxies (i.e. CSI, BCS, and FKLI) in influencing various aggregate stock market indices in Malaysia. The proposed sentiment proxies in relation to stock returns are statistically analyzed using mean-based (OLS) and quantile regression $(\mathrm{QR})$ methods to uncover the relationships accross full range of stock market returns conditional distributions. In the analysis, we examine the possible multidimensional association of various conditional sentiments (i.e. average, sentiment states, market states, and interaction between sentiment and market states) on size (i.e. big firms vs. small firms) and industry (i.e. defensive vs. speculative) segmented data. The OLS analysis does not provide conclusive significant association of sentiment to returns but the QR analysis reveal emerging patterns of sentiment heterogeneity roles. Specifically, the QR analysis reveal an asymmetric association between sentiment to returns with U-curve pattern from negative magnitude in the lower quantiles and positive magnitude in the upper quantiles. The findings are not only consistent with the current hypothesis that sentiment risk strongly affects the small firms and speculative industry but also the big firms. The sentiment-return associations are statistically significant in extreme lower quantiles and in extreme upper quantiles of return distributions. These patterns are consistent with theoretical postulates of prospect theory and evidence of assymetric overreaction of Asian investors to sentiment. Overall, the findings from this paper provide new insights for theoretical understanding and practical application of sentiment risk in the stock market.
\end{abstract}

Keywords: Behavioral finance, Behavioral risks, Investor sentiment, Stock market, Quantile regression.

\section{INTRODUCTION}

Earlier economic scholars (Keynes, 1936) and investment practitioners (Graham and Dodd, 1940) stated that investor sentiment is an important behavioral risk believed to influence investor decision and it is consequently reflected in asset prices and financial markets behavior. Their ideas are directly quoted below.

"...the market is subject to waves of optimistic and pessimistic sentiment, which are unreasonable and yet in a sense legitimate where no solid basis exists for a sound 
calculation...” (Keynes, 1936, p. 154)... “...the market is a voting machine, where countless individuals register choices which are the product partly of reason and partly of emotion [sentiment]..." (Graham and Dodd, 1940, p. 27)

However, this idea has been neglected and assumed to play no role in the modern finance paradigm which is guided by investor rationality and market efficiency assumptions that dominate the thinking of academicians, practitioners, and policy makers since the 1950s. Scholar attention to sentiment risk only re-emerged in the 1980s under the behavioral finance paradigm with the theoretical assumption that an investor is boundedly rational, which causes the market not to be perfectly efficient sometimes. One strand of behavioral finance research is the understanding of behavioral risks affecting asset prices and financial markets. Earlier work classified this as noise trader risk (Shleifer and Summers, 1990) arising out of animal spirits (Black, 1989) and later, growing behavioral finance scholarly works provide theoretical justification and empirical evidence that stock prices reflect both fundamental and behavioral risk components (Bos and Anderson, 1988; Fisher and Statman, 2004; Statman, Fisher and Anginer, 2008), among others. These works show that sentiment is an important behavioral risk that not only affects price per se but also causes temporary market instability (Dow, 2011) and directly leads to inefficiency patterns in the financial markets (Shleifer, 2000). Given this background, sentiment cannot be insolated from the risk measurement model (Dow, 2011) of asset prices and investment portfolio management.

In behavioral finance works, investor sentiment is broadly defined as a ratio expressing an opinion (Solt and Statman, 1988), irrational beliefs (Morck, Shleifer and Vishny, 1990), erroneous beliefs (Barberies, Shleifer and Vishny, 1998), and investor opinions (Chang, Faff and Hwang, 2012) on the consensus forecasts (Berbaries, Shleifer and Vishny, 1998) which are not justified by information at hand that influence expectation for future cash flows and investment risk. The investor expectation on future market states could be optimistic or pessimistic (Lee, Shleifer and Thaler, 1991; Baker and Wurgler, 2006). These expectations accordingly adjust investor risk tolerance (Edelen, Marcus, and Tehranian, 2010) or risk aversion level (Murphy, 2012) and propensity to speculate (Kurov, 2010) that underlies underreaction or overreaction of investors to news (Barberies et al. 1998). Accordingly, demand and supply for stocks that are partly influenced by these sentiment beliefs will cause the stock prices to deviate from their true fundamental values (De Long, Shleifer, Summers, and Waldmann, 1990). Taking all these ideas together, sentiment risk could be regarded as the systematic behavioral risk that affects security values and stock market behavior. Despite the practical importance of sentiment risk, sentiment theory is still in its infancy with the following theoretical and empirical gaps. The important theoretical gaps are: firstly, the measurement and quantification of sentiment effects (Baker and Wurgler, 2007); secondly, the identification of stocks which are more affected by sentiment risk (Baker and Wurgler, 2007); and thirdly, theorization of investor sentiment and stock market relationships (Bughdart, 2011). From the empirical perspective, evidence of sentiment and returns relationship is inconclusive.

In this paper, we address the above sentiment research gaps with a specific focus on the Malaysian stock market due to the following reasons. Firstly, earlier scholars have indicated that due to cultural forces (i.e. more prone to herding, overreaction, low institutional involvement, and gambling), Asians are more affected by behavioral biases in their decision making (Yates, 
Lee and Bush, 1997; Kim and Nofsinger, 2008) and that investor sentiment is more pronounced in these countries (Zouaoui, Nouyrigat, and Beer, 2011). In this context, being culturally collectivist (Statman, 2008), Malaysians are more to herding behavior (Chui, Titman and Wei, 2010). Secondly, the Malaysian stock market is highly denominated by retail investors which are believed to be more affected by behavioral biases due to lack of knowledge and skills in stock market investment. Thirdly, exploration of the possible influence of behavioral risks on asset prices and stock market behavior is warranted as existing studies indicated that the Malaysian stock market is also noted to be less sensitive to changes in fundamental factors and more prone to speculative trading effect (Ariff, Mohamad and Nassir, 1998), and the stock market sometimes portrays an evidence of irrationality and inefficiency (Nassir, 2002). So far, there are no endorsed proxies for investor sentiment in Malaysia, but consumer sentiment index (CSI), business condition servay (BCS) and stock futures index (FKLI) are seen as highly possible proxies for investor sentiment (see Mat Nor, Ibrahim and Rashid, 2013; Tuyon, Ahmad, Matahir; 2015). Selections of these variables are theoretically and empirically derived as non-economic factors that possibly influence investors' thought and indirectly influence stock prices. This is in line with the idea of Bormann (2013) which states that sentiment proxies can be any kind that can be referred by investors to inform judgment about the future. Specifically, the CSI and BCS represents the opinion of consumers and business owners or entrepreneurs respectively, while the FKLI represents investors' expectation about future prospects of the stock market. Use of this variable as a sentiment proxy is in line with Safa and Maroney (2012) study. In the Malaysian investment environment, these three variables have been widely reported by economists, analysts and journalists and believed to be highly attended by professional and retail investors. However, these works are still at the infancy stage and require further theoretical and empirical scrutiny.

This research extends the works of Tuyon and Ahmad (2014) that provides discussion on the theoretical relations between sentiment and stock market activity and Tuyon et al. (2015) that proposed CSI, BSI and FKLI as possible sentiment proxies. The objectives of this paper are to theoretically and empirically examine the heterogeneity roles of these sentiment proxies on aggregate stock market indice returns in the Malaysian setting. This work involves two stages. Firstly, we theoretically establish the association and causation relationships to justify their economic significance. Secondly, we examine the statistical significance of the association using both mean-based and quantile-based regression analyses to uncover possible multidimensional relationships between them. The findings from this research provide both confirmation and disagreement to the existing sentiment theory. In addition, this study also highlights some emerging patterns of sentiment heterogeneity roles across different conditional perspectives. We believe that this study provides new insights for the theoretical and practical applications of sentiment risk, particularly in the Malaysian context.

The remainder of this paper is organized as follows: In the next section 2, we theoretically establish the possible association and causation between sentiment proxies and returns. In the subsequent section 3, data descriptions and econometric methods for analysis are elaborated. This is followed by findings and discussions in section 4. Section 5 provides the syntheses of findings to existing theory, evidences and practical implications. The final section 5 concludes with possible future research ideas. 


\section{THEORETICAL FOUNDATIONS}

In theorizing association and relationships between sentiment to returns, a priori theory must be used to establish potential association and causal mechanisms between these variables. Accordingly, in what follows, we theoretically establish the possible association and causation of sentiments to returns based on the theoretical framework of asset return generating process as postulated by the discounted cash flow model i.e. $p=\sum_{t=1}^{n} \frac{C F_{t}}{(1+R)^{t}}$ of Gordon and Shapiro (1956).

The role of irrational sentiments in inducing investor expectations through this model is discussed in Tuyon et al. (2015). In this paper, first, we use the theory of association to establish the association relationships of sentiment to returns. Statistically speaking, association refers to a linkage among variables (in this case, sentiment to returns) through positive or negative association relationships. In a positive association, direct relationships among variables are expected, whereas a negative association indicates inverse relationships between variables. In the Malaysian stock market environment, CSI, BCS, and FKLI are publicly available, commented on by economists, analysts, journalists and investment bloggers, and believed to be attended by both professional and retail investors as a potential valuable information in forecasting the future direction of the stock market. In this regard, in Tuyon and Ahmad (2014) we proposed the cognitive neuroscience based theory of mind (TOM) and cognitive psychology based theory of causation called the $\mathrm{ABC}$ model to theorize the association between sentiment and returns. Both these theories can justify the origin, cause and consequence of sentiment on investor thinking and behavior as well as explain their possible influence on the formation of share prices as illustrated in Figure 1 below. For brevity, these sentiment proxies provide opinions that influence the mind of the investor through an affective system and consequently induce investor and market behaviors accordingly.

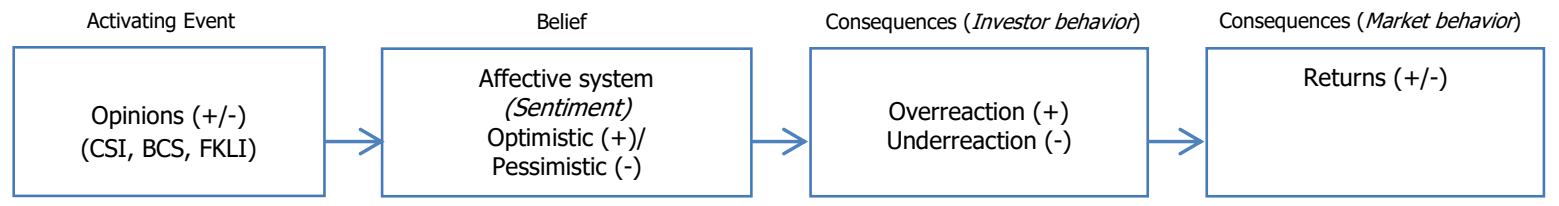

Figure 1: Conceptual framework for association relationships

The above framework illustrates the causation relation between sentiment and return generations. The state of the sentiment (i.e. optimism/neutral/pessimism) will induce trading behavior which will influence changes in trading volume accordingly. Changes in trading volume will cause changes in stock prices that will in turn create volatility changes and price adjustments, which then determine stock returns. Should sentiment affect the aggregate market returns, changes in sentiment should be positively related to contemporaneous stock market returns and negatively related to future stock market returns (Baker and Wurgler, 2006; 2007). Based on the above association relationships framework, the mathematical and linear relationship between sentiment and returns can be written in the following equations $1 \mathrm{a}$ and $1 \mathrm{~b}$ respectively. 


$$
\begin{aligned}
& R_{i, t}=f(S E N T) \ldots \ldots \ldots \\
& R_{i, t}=\alpha+\beta S E N T+e_{t}
\end{aligned}
$$

\section{HETEROGENEITY ROLES OF INVESTOR SENTIMENTS}

Recent empirical evidence point to the heterogeneity roles of investor sentiment on stock returns. Literally, heterogeneous means non-uniformity, diversity, or variety (Thefreedictionary.com). Investor sentiment heterogeneity refers to the different effects of sentiment on returns given different conditions as discussed below.

Firstly, the positive-negative asymmetry effect. Sentiment induces both positive and negative feelings on the part of the investor that directly influence their decision. In this regard, positive sentiment induces optimistic choices and negative sentiment induces pessimistic choices (Arkes, Herren and Isen, 1988). One important psychology-based hypothesis (i.e. negativity bias) is that humans place greater weightage on negative information compared to positive information (Kanouse, 1984). Three reasons have been offered to support this hypothesis (Siegrist and Cvetkovich, 2001). First, negative information is more diagnostic than positive information. Second, due to strong aversion to loss, people place greater weightage on negative information more to avoid losses. Third, negative information is seen as more credible because it is not released to persuade and influence. Positive effect is known in positive psychology literature as the positivity effect (Fredrickson, 2001) of which characteristics include confidence, optimism, and self-efficacy (Lyubomirsky and King, 2005). Theoretically, positive effect is believed to prompt the individual to engage with their environment (Fredrickson, 2001) and facilitate happiness that will lead to success (Lyubomirsky and King, 2005). In behavioral finance research, the validity of stronger negative sentiment impact is documented in Akhtar, Faff and Oliver (2011), while the validity of positive sentiment hypothesis has also been supported in behavioral finance research (see Huang and Goo, 2008; Teng and Liu, 2013; Kaplanski, Levy, Veld, and Veld-Merkoulova, 2015). In fact, the positive and negative effects are in line with the prospect theory of Kahneman and Tversky (1979) which theorize that human decisions are based on potential losses and gains and they weigh losses more than gains (Simon, Stefan and Dirk, 2015) which is a widespread and robust phenomenon (Peng, Miao, and Xiao, 2013).

Secondly, sentiment has a different effect on firm's stock returns. In reference to Baker and Wurgler $(2006$; 2007), in a contemporaneous relationship, sentiment risk places more vulnerability on stocks that are speculative and difficult to value and arbitrage (i.e. newer, smaller, more volatile, distressed, extreme growth) compared to safe and easy to arbitrage stocks (i.e. regulated utilities, firm with long earning history, stable dividend). In addition, recent research provide evidence that firms in a different industry are reported to have different influential sentiment effect (Kaplanski and Levy, 2010; Chou, Ho and Ko, 2012; Chen, Chen and Lee, 2013; Dash and Mahakud, 2013) but behavioral explanation for this issue is not justified.

Thirdly, other heterogeneous forces, emerging recent evidence points to the heterogeneity roles of sentiment due to the following forces. Firstly, it may be due to different proxies used for sentiment used. Secondly, it may be due to various issues of heterogeneity including difference in economic conditions, market conditions, sentiment states, investor groups, company size, company salience, and industry groups. As such, in the empirical analysis, the above issues need to be taken into consideration to derive economic and statistical meaning on the role of sentiment. We summarize these evidences in the following Table 1 below. 
Table 1: Analysis of investor sentiment heterogeneous effects on stock returns

\begin{tabular}{|c|c|c|c|c|}
\hline \multirow{2}{*}{$\begin{array}{l}\text { Heterogeneous } \\
\text { Determinants }\end{array}$} & \multirow[t]{2}{*}{ Environment/Condition } & \multicolumn{2}{|c|}{ Sentiment effects on returns } & \multirow[t]{2}{*}{ Studies } \\
\hline & & Significant & $\begin{array}{l}\text { Degree of } \\
\text { biasness }\end{array}$ & \\
\hline \multirow[t]{2}{*}{$\begin{array}{l}\text { Economic } \\
\text { condition }\end{array}$} & Recession & $\mathrm{No} / \mathrm{Yes}$ & High & $\begin{array}{l}\text { Chung, Hung, and Yeh (2012); } \\
\text { Garcia (2013) }\end{array}$ \\
\hline & Expansion & Yes & Low & \\
\hline \multirow[t]{2}{*}{ Market condition } & Bear Market & Yes & High & Kurov (2010) \\
\hline & Bull Market & Yes & Low & \\
\hline \multirow{2}{*}{$\begin{array}{l}\text { Information } \\
\text { states }\end{array}$} & Negative & Yes & High & Akhtar, Faff and Oliver (2011) \\
\hline & Positive & Yes & Low & \\
\hline \multirow[t]{2}{*}{ Sentiment states } & Pessimism & Yes & High & Stambaugh, Yu and Yuan (2012) \\
\hline & Optimism & Yes & Low & \\
\hline \multirow[t]{2}{*}{ Investor group } & Retail & Yes & High & Lee, Shleifer and Thaler (1991); \\
\hline & Institutional & Yes & Low & $\begin{array}{l}\text { Kumar and Lee (2006); Schmeling } \\
(2007)\end{array}$ \\
\hline \multirow[t]{2}{*}{ Company size } & Small & Yes & High & Baker and Wurgler (2006; 2007); \\
\hline & Big & Yes & Low & $\begin{array}{l}\text { Lemmon and Portniaguina (2006); } \\
\text { Kaplanski and Levy (2010) }\end{array}$ \\
\hline \multirow[t]{2}{*}{ Company salient } & High Salient & Yes & High & Akhtar, $\quad$ Faff, $\quad$ Oliver \\
\hline & Low Salient & Yes & Low & Subrahmanyam (2012) \\
\hline \multirow[t]{2}{*}{ Industry group } & Less stable industries & Yes & High & Kaplanski and Levy (2010) \\
\hline & Stable industries & Yes & Low & \\
\hline \multirow[t]{2}{*}{ Cultural traits } & Collectivism & Yes & High & Statman (2008); Statman and Weng \\
\hline & Individualism & Yes & Low & $(2010)$ \\
\hline
\end{tabular}

Note: Summary of the expectations about the effect of investor sentiment according to the environment or conditions.

Given the above discussion, understanding sentiment heterogeneity role is important. Here we propose two possible approaches to detect sentiment heterogeneity role. First, by employing segmentation of analysis based on the homogeneous nature of data and conditions as pointed by Elton and Gruber (1970). The idea is to disaggregate data into meaningful homogeneous groups in order to improve theoretical understanding and empirical forecast. These indicate the appropriateness for describing stock returns based on industry factor, group factor and firm factor and the need to group stocks based on these homogeneous characteristics to improve forecasting (Elton and Gruber, 1971; Martin and Klemkosky, 1976).

Second, using quantile regression to uncover data behavior along the full spectrum of data distribution. Many have acknowledged that the world is complex and we are leaving in a world of extremes. However, research is still generally based on Gaussian statistics that assume normal distributions with finite means and variance of data characteristics that ignore complexity and extremes. This would potentially lead to inaccuracy and findings would be irrelevant to practitioners in the real world (Andriani and McKelvey, 2007). In a similar vein, Woodside (2013) called for a paradigm shift from symmetric to asymmetric thinking in data analysis for theory crafting and testing. A potential solution to understand complexity is to see and interpret the world beyond merely the means and explore the heterogeneity of relationships. Statistical methods that can be use to examine the data properties beyond the means is the quantile regression (QR). QR is a type of nonparametric statistics ( $\mathrm{Li}, 2014)$ which was pioneered by Koenker \& Bassett (1978). QR can be applied to address the problems of nonlinearity and 
heterogeneity of data properties (Haupt \& Petring, 2011). QR is able to analyse the entire distribution of data without the need to trim the outliers. As such, it has the advantage of providing a more complete relationship in regression analysis since the analyses consider both the means and the heavy-tailed distributions ( $\mathrm{Li}, 2014)$. Review of application of QR in various research domains is provided in $\mathrm{Yu}$ and Stander (2003). In modern finance paradigm, financial data behaviors are assumed be constant and well distributed according to Gaussian statistic assumptions. However, there are common characteristics of stock returns data that violated this assumption: autocorrelation, collinearity, fat tails, volatility clustering, gain/loss asymmetry, time variations in risk premium, skewness and excess kurtosis which are collectively known as the stylized statistical properties of asset returns (Cont, 2001).

\section{DATA AND METHODS}

\subsection{Data description and segmentation}

In this research, three different proxies of investor sentiment are drawn from consumer surveys (CSI), business surveys (BCI), and futures investors opinion (FKLI). Due to the availability and standardization of data, the periods of the series are limited from 1996:01 to 2014:12. Data for CSI and BCS are obtained from MIER, while the rest are obtained from Bloomberg. The original data for CSI and BCS are quarterly data and transformed to monthly frequency for consistency using the interpolation method ${ }^{1}$. As for the equity data, we use 12 aggregate indices data and returns are calculated as $R_{t}^{1, i}\left(\frac{P_{t}}{P_{t-1}}\right) * 100$

In the analysis, we segmented the indices group based on size and industry. Index size classification is based on the definition used by Baker and Wurgler (2007). Industry sectors are classified into two groups as being either cyclical or defensive (Dirks, 1958; Becher, Jensen and Mercer, 2008; Held, 2009; Nagy and Ruban, 2011). Sector characteristics are expected to be different. Specifically, defensive sectors are expected to be less sensitive to macroeconomic and market fluctuations. On the other hand, the cyclical sectors are more sensitive to the macroeconomic and market developments (Becher, et al. 2008; Held, 2009; Nagy and Ruban, 2011). From the size perspective, firms can be categorised into: (i) speculative firms (BM70, BM Small Cap and BM Fledgling) which are characterized as small-capitalized firms, speculative in nature, with volatile earnings, lower prices, and extreme growth, and (ii) stable firms (BM KLCI, BM100, and BM Emas) which are characterized as large capitalized firms, with higher prices. Industries can be categorised into: (i) cyclical industries (property, finance, and construction) which are more sensitive to the macroeconomic and market developments as well as having higher correlation with the market, and (ii) defensive industries (consumer, plantation, and trade and services) which are expected to be less sensitive to macroeconomic and market fluctuations as well as having lower correlation with the market. We also examine sentiment heterogeneity during the stock market crisis measured using dummy crisis which is equal to one for periods under crisis and zero otherwise. The pre-determined crisis market states are: Asian financial crisis (28/02/97 to 1/09/98), September 11 attack and Technology slump

${ }^{1}$ There are various alternatives available for statistical data disaggregation procedures. This research use the interpolation method because of its advantage of having a lower mean absolute error and root mean squared error compared to other methods as summarized in Chan's (1993) comparative study.

(C) 2016 UNIMAS All Rights Reserved $57 \mid \mathrm{P}$ a g e 
(09/04/01 to $23 / 04 / 02)$, SARS (23/04/02 to $11 / 03 / 03)$, and Subprime crisis (11/01/08 to 17/10/08).

Table 2: Descriptive statistics

\begin{tabular}{|c|c|c|c|c|c|c|c|c|c|c|c|}
\hline $\begin{array}{l}\text { Segmentati } \\
\text { on }\end{array}$ & Indices & $\begin{array}{l}\text { Mea } \\
\mathrm{n}\end{array}$ & Median & $\begin{array}{l}\text { Maximu } \\
\mathrm{m}\end{array}$ & $\begin{array}{l}\text { Minimu } \\
\mathrm{m}\end{array}$ & Std. Dev. & Skewness & $\begin{array}{l}\text { Kurtosi } \\
\mathrm{s}\end{array}$ & $\begin{array}{l}\text { JB- } \\
\text { Stats } \\
\end{array}$ & Prob. & Sum \\
\hline \multirow{3}{*}{ Big Firms } & KLCI & 0.19 & 0.87 & 29.44 & -28.46 & 6.85 & -0.07 & 7.3 & 173.48 & 0 & 42.71 \\
\hline & BM100 & 0.21 & 0.69 & 29.4 & -27.33 & 7.03 & -0.12 & 7.03 & 153.1 & 0 & 48.34 \\
\hline & EMAS & 0.15 & 0.69 & 30.73 & -28.61 & 7.23 & -0.04 & 7.33 & 175.57 & 0 & 32.94 \\
\hline \multirow{3}{*}{ Small Firms } & BM70 & 0.11 & 0.62 & 38.97 & -35 & 8.15 & -0.02 & 7.93 & 227.96 & 0 & 24.1 \\
\hline & BMSC & -0.05 & 0.15 & 44.19 & -33.36 & 9.22 & 0.37 & 7.04 & 158.25 & 0 & -10.89 \\
\hline & BMFL & -0.03 & 0.24 & 44.05 & -44.11 & 9.94 & 0.23 & 8.15 & 250.51 & 0 & -7.5 \\
\hline \multirow{3}{*}{$\begin{array}{l}\text { Defensive } \\
\text { Industry }\end{array}$} & $\mathrm{CSU}$ & 0.4 & 0.74 & 25.06 & -31.33 & 5.7 & -0.54 & 11.31 & 658.44 & 0 & 90.4 \\
\hline & PLN & 0.47 & 0.97 & 27.75 & -32.43 & 7.09 & -0.82 & 7.07 & 180.66 & 0 & 106.38 \\
\hline & SER & 0.1 & 0.6 & 29.76 & -27.31 & 7.08 & -0.08 & 6.43 & 110.63 & 0 & 22.09 \\
\hline \multirow{3}{*}{$\begin{array}{l}\text { Speculative } \\
\text { Industry }\end{array}$} & PRP & -0.28 & 0.09 & 39.69 & -31.93 & 8.93 & 0.3 & 6.37 & 109.71 & 0 & -62.71 \\
\hline & FIN & 0.62 & 0.84 & 50.59 & -38.55 & 8.91 & 0.52 & 10.97 & 606.13 & 0 & 59.43 \\
\hline & $\mathrm{CON}$ & -0.22 & 0.36 & 50.55 & -47.19 & 10.25 & 0.18 & 9.84 & 439.37 & 0 & -50.01 \\
\hline \multirow{3}{*}{$\begin{array}{l}\text { Sentiment } \\
\text { (Average) }\end{array}$} & CSI & -0.2 & 0.15 & 12.14 & -20.25 & 3.94 & -0.79 & 7.48 & 211.19 & 0 & -44.48 \\
\hline & $\mathrm{BCS}$ & 0.21 & 0.18 & 21.9 & -22.74 & 5.31 & 0.2 & 8.22 & 256.67 & 0 & 46.63 \\
\hline & FKLI & 0.23 & 0.73 & 29.38 & -28.08 & 6.86 & -0.12 & 7.42 & 184.05 & 0 & 52.22 \\
\hline \multirow{3}{*}{$\begin{array}{l}\text { Sentiment } \\
\text { (in non- } \\
\text { crisis) }\end{array}$} & $\mathrm{CSI} * \mathrm{NC}$ & 0.12 & 0.00 & 11.77 & -10.69 & 2.99 & -0.04 & 6.46 & 112.05 & 0 & 27.59 \\
\hline & $\mathrm{BCS} * \mathrm{NC}$ & 0.16 & 0.00 & 21.90 & -22.74 & 4.38 & -0.01 & 13.19 & 974.23 & 0 & 35.84 \\
\hline & FKLI*NC & 1.03 & 0.00 & 29.38 & -16.16 & 4.77 & 1.40 & 11.39 & 734.30 & 0 & 232.54 \\
\hline \multirow{4}{*}{$\begin{array}{l}\text { Sentiment } \\
\text { (in crisis) }\end{array}$} & & & & & & & & & 7073.1 & & \\
\hline & $\mathrm{CSI}{ }^{*} \mathrm{C}$ & -0.32 & 0.00 & 12.14 & -20.25 & 2.55 & -3.22 & 29.70 & $\begin{array}{c}0 \\
0\end{array}$ & 0 & -72.07 \\
\hline & $\mathrm{BCS} * \mathrm{C}$ & 0.05 & 0.00 & 19.63 & -16.31 & 3.00 & 1.42 & 20.81 & $\begin{array}{c}3048.5 \\
2\end{array}$ & 0 & 10.79 \\
\hline & FKLI* ${ }^{*} \mathrm{C}$ & -0.08 & 0.00 & 27.18 & -28.08 & 4.76 & -1.61 & 17.75 & $\begin{array}{c}2137.0 \\
1\end{array}$ & 0 & 180.32 \\
\hline
\end{tabular}

Notes: The above 12 aggregate indices are based on the classification of FTSE-Bursa Malaysia. KLCI, BM100, and EMAS comprise large capitalized firms. BM70, BMSC (BM Small Cap), and BMFL (BM Fledgling) represent small capitalized listed firms. The full name for the industrial indices are as follows: CSU (consumer), PLN (plantation), SER (trading and services), TIN (mining), PRP (properties), FIN (Finance), $\mathrm{CON}$ (construction). $\mathrm{NC}$ and $\mathrm{C}$ denotes non-crisis and crisis market states respectively. Number of observations is equal to 255 for all variables.

The statistical nature of the data for stock market indices confirm the theoretical reasoning for the segmentations. Specifically, big and defensive industry returns consistently recorded a positive mean value consistent with their stability prediction. The small firms and speculative industry groups recorded non-consistent values which confirmed to the unstable nature of the firms and industries in these groups. The small and speculative industries also recorded the highest maximum returns and lowest minimum returns compared to big firms and defensive industries. This is consistent with the theoretical prediction that the former firm groups are highly attractive and affordable to retail investors. There is also a notable difference between sentiment during non-crisis and in crisis market states. In addition, the risk (as measured by standard deviation) is consistent with the theoretical expectations that small firms and speculative industry groups are riskier compared to big firms and defensive industry groups. The significant value of JB statistic indicates that the residual distributions are not normal. This can be complemented with evidence of fat tails as shown by unstandardized skeweness statistics across different sub-groups and positive kurtosis statistics which are higher than the normality benchmark of 3 . These are in line with the existing expectation of the nature of stock market data and within the belief of the behavioral finance paradigm.

\subsection{Empirical Model}


According to the association and causation framework, the empirical molde of the return generation process can be established as in the following autoregressive model as in equation 2 , where, $R_{t}^{1}$ is the $\log$ of changes of Bursa Malaysia indexes returns, $\alpha_{0}$ and $\beta_{1}$ are the parameters, $R_{t-1}^{1, t}$ is the lag return as a control variable measuring past price influence on today's stock returns, Sentiments, SENT $T_{t}=f(C S I, B C S, F K L I)$ is the log of changes in investor sentiment indicators namely consumers' survey, business survey and stock futures index, and $\varepsilon_{t}$ denotes error terms that represents possible determinants of other non-accounted variables on stock indices returns.

$$
R_{t}^{1, t}=\alpha_{0}+R_{t-1}^{1, t}+\beta_{i} S E N T_{t}+\varepsilon_{t}
$$

The following Figure 2 illustrates the empirical movement patterns of the proposed sentiment proxies (i.e. CSI, BCS, and FKLI) with the Malaysian main stock market index (i.e. KLCI) spanning from 1996:01 to 2014:12. In what follows, the validity of the statistical relationships between sentiment proxies to 12 stock market indices returns are examined using correlation and regression methods. The statistical analyses are complemented with behavioral insights to uncover the heterogeneity roles of sentiments in inducing stock returns between different market states, size and industry characteristics as mentioned in the earlier theoretical section.

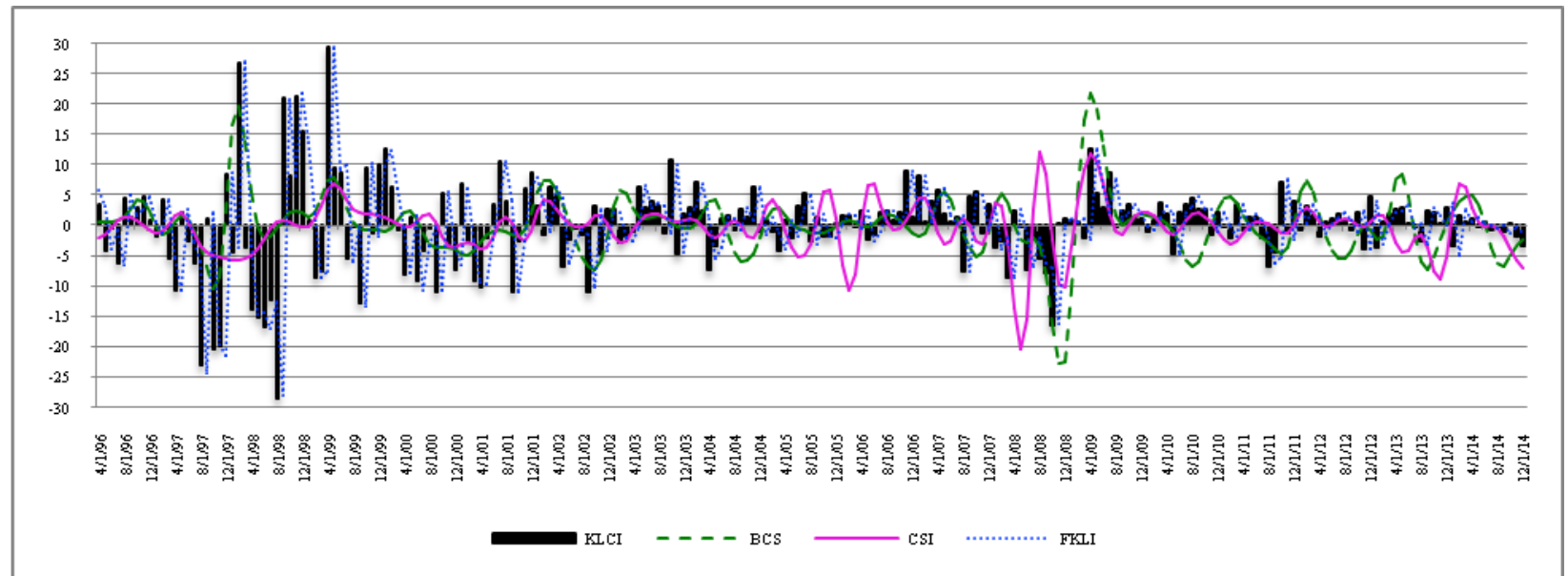

Figure 2: Pictorial relationship of three sentiment proxies (i.e. BCS, CSI, and FKLI) with the Malaysian stock market indicator (KLCI).

\section{Diagnostic Statistics}

The variables order of integration are inspected using the Augmented Dickey-Fuller (ADF) and Phillips-Perron (PP) unit root tests. We inspected variables series at level and difference with without trends and intercepts. We confirm that variables order of integration are with a mixture of $I(0)$ or $I(1)$ and non with $I(2)$. As for unfulfillment of normality, this condition can be ignored if sample is higher than $30^{2}$ and our sample is large enough to rule out this condition. In addition, we also examine the Q-Q plots that confirm the non-normality dispersion of the data. These analyses are not reported here to conserve space but are available upon request.

${ }^{2}$ Referred from ARDL approach to cointegration by Noman Arshed. ( https://nomanarshed.wordpress.com/2014/11/16/a-manual-for-ardl-approach-to-cointegration/) (C) 2016 UNIMAS All Rights Reserved 


\section{Correlation and Regression Analysis}

Based on the stationary data series, we performed the association analysis by employing the correlation and regression analyses to examine the nature of association relationships between sentiments proxies $\left(X_{i}\right)$ to returns $\left(Y_{i}\right)$. In reference to Puth, Neuhauser, and Ruxton (2014), we examine the signs of association by using the Pearson correlation $(r)$ calculated as in equation 4 below. The possible associations are: perfect positive association $\left({ }_{W F}=1\right)$, imperfect positive association $\left(0<r_{X Y}<1\right)$, no association $\left(r_{X Y}=0\right)$, imperfect negative association $\left(-1<r_{W Z}<0\right)$, and perfect negative association $\left({ }^{T_{W F}}=-1\right)$. We perform the association analysis based on three sub-samples namely overall, crisis, and non-crisis periods to examine the possible heterogeneous association between variables of interest.

$$
\begin{aligned}
& r=\frac{\sum_{i=1}^{W}\left\{\left(X_{\bar{i}}-\bar{X}\right)\left(Y_{\bar{i}}-\bar{Y}\right)\right\}}{\sqrt{\sum_{i=1}^{W}\left(X_{\bar{i}}-\bar{X}\right)^{2}} \sqrt{\sum_{i=1}^{W}\left(Y_{\bar{i}}-\bar{Y}\right)^{2}}} \\
& \text { Where, } \quad \bar{X}=\frac{1}{N} \sum_{i=1}^{N} X_{\bar{i}} \text { and } \bar{Y}=\frac{1}{N} \sum_{i=1}^{N} Y_{\bar{i}}
\end{aligned}
$$

Since the correlation does not tell us about the magnitude of association, the strengths of associations are further inspected using the ordinary least square (OLS) regression analysis as in equation 5 below, where $R_{t}^{l, i}$ is the respective indices returns, $R_{t-1}^{l, i}$ is a lagged return as a control variable, $C S I, B C S$, and $F K L I$ are the sentiment proxies, $\varepsilon_{t}$ is the error term. The sample period, $t$ $=1,2, \ldots, T$ and $\beta_{1,2,2,4}$ are unknown population coefficients. The regression analysis comes with the following assumptions: the distribution term has zero mean, the disturbance variance is consistent for all observations (i.e. homoskedastic), the disturbance corresponding to different observations have zero correlation (i.e. no autocorrelation), $X_{t}$ is non-stochastic, $Y_{t}$ is stationary, the error terms (disturbances) are uncorrelated with explanatory variables, there is no perfect linear relationship between the explanatory variables (i.e. no multicollinearity), and the disturbances are normally distributed. This test is only efficient if the data properties obeyed the time series data assumptions of independently distributed random white noise process drawn from the normal distribution, that is $\varepsilon_{t} \sim I N\left(0, \sigma_{\varepsilon}^{2}\right)$, otherwise it represents inefficient and biased inferences. We perform seven conditional analyses: average sentiment (4a), positive sentiment (4b), negative sentiment (4c), positive sentiment in non-crisis (4d), positive sentiment in crisis (4e), negative sentiment in non-crisis (4f), and negative sentiment in crisis $(4 \mathrm{~g})$.

$$
\begin{aligned}
& R_{t}^{l, \pi}=a_{0}+\beta_{1} R_{t-1}^{l, i}+\beta_{2} C S I_{t}+\beta_{a} B C S_{t}+\beta_{4} F^{2} L L I_{t}+\varepsilon_{t} \\
& R_{t}^{l, \bar{i}}=\alpha_{0}+\beta_{1} R_{t-1}^{l, i}+\beta_{2} C S I_{t}^{+}+\beta_{a} B C S_{t}^{+}+\beta_{4} F K L I_{t}^{+}+\varepsilon_{t} \\
& R_{t}^{L, i}=\alpha_{0}+\beta_{1} R_{t-1}^{i n}+\beta_{2} C S I_{t}^{-}+\beta_{a} B C S_{t}^{-}+\beta_{4} F K L I_{t}^{-}+\varepsilon_{t} \\
& R_{t}^{l, i}=a_{0}+\beta_{1} R_{t-1}^{l, n_{1}}+\beta_{2} \operatorname{CSI}_{t}^{+} * N C+\beta_{3} B C S_{t}^{+} * N C+\beta_{4} F K L I_{t}^{+} * N C+\varepsilon_{t} \\
& R_{t}^{l, i}=a_{0}+\beta_{1} R_{t-1}^{l, i}+\beta_{2} C S I_{t}^{+} * C+\beta_{3} B C S_{t}^{+} * C+\beta_{4} F K L I_{t}^{+} * C+\varepsilon_{t} \\
& R_{t}^{l, i}=\alpha_{0}+\beta_{1} R_{t-1}^{l, i}+\beta_{2} C S I_{t}^{-} * N C+\beta_{a} B C S_{t}^{-} * N C+\beta_{4} F K L I_{t}^{-} * N C+\varepsilon_{t}
\end{aligned}
$$

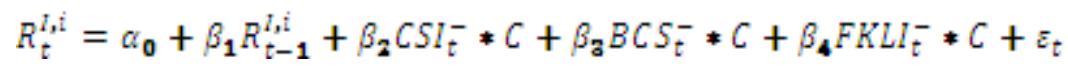


Similarly, the quantile regression $(\mathrm{QR})$ models were also performed on the above seven conditions. In reference to Koenker and Bassett (1987), the basic linear model (5a) and its QR representation, the ${ }^{\theta}$ th conditional quantile of $y_{i}$ given $x_{i}(5 b)$ is written as follows:

$$
\begin{gathered}
y_{t}=x_{t} \beta_{\theta}+\varepsilon_{\theta} \\
Q_{\theta}\left(y_{i} \mid x_{i}\right)=x_{t}^{*} \beta_{\theta}
\end{gathered}
$$

Where $\beta_{\theta}$ is an unknown $\mathrm{k} \times 1$ vector of regression parameters associated with the ${ }^{\theta}$ th percentile, $y_{i}$ is the dependent variable and $x_{i}$ is a $\mathrm{k} \mathrm{x} 1$ vector of independent variables, with the model assumption that the conditional $\theta$ th quantile of the error term is equal to zero i.e. $Q_{\theta}\left(\varepsilon_{i} \mid x_{i}\right)=0$. In this model, various quantiles can be inspected from $0-1$ with ${ }^{\theta}=0.5$ known as the median regression. Quantiles below the median point are known as lower quantiles and quantiles above median are called upper quantiles.

\section{RESULTS AND DISCUSSIONS}

In the first stage of analysis, we perform the correlation analysis of various sentiment conditional to all stock market indices that are segmented into four groups namely big firms, small firms, defensive industries, and speculative industries. The sentiment conditional analyses are segmented into seven conditions as follows: average sentiments which represent all values of CSI, BCS and FKLI; positive sentiments that are determined using dummy variable; negative sentiments that are determined using dummy variable; positive sentiment in non-crisis market states which is examined by interacting the positive sentiment dummy and non-crisis market states dummy; positive sentiment in crisis market states which is measured by interacting the positive sentiment dummy with crisis market states dummy; negative sentiment in non-crisis market states which is examined by interacting the negative sentiment dummy and non-crisis market states dummy; and negative sentiment in crisis market states which is measured by interacting the negative sentiment dummy with crisis market states dummy. The correlation analyses results are as summarized in the following Table 3. The three sentiment proxies are also positively correlated to each other, where CSI-BCS correlation is 0.33, CSI-FKLI correlation is 0.15 , and BCS-FKLI correlation is 0.29 . In the following correlation table, we only report the sentiment conditionals associations to the segmented four groups of stock indices data. The correlation table within sentiment variables is unreported due to space constraints.

\begin{tabular}{|c|c|c|c|c|c|}
\hline Segmentation & Variables & Big Firms & Small Firms & Defensive Industries & Speculative Industries \\
\hline
\end{tabular}

Table 3: Summary of correlation analysis 


\begin{tabular}{|c|c|c|c|c|c|c|c|c|c|c|c|c|c|}
\hline & & KLCI & $\begin{array}{r}\text { BM1 } \\
00\end{array}$ & $\begin{array}{r}\text { EMA } \\
\mathrm{S}\end{array}$ & $\begin{array}{r}\text { BM7 } \\
0\end{array}$ & $\begin{array}{r}\text { BMS } \\
\mathrm{C}\end{array}$ & $\begin{array}{r}\mathrm{BMF} \\
\mathrm{L}\end{array}$ & $\mathrm{CSU}$ & PLN & SER & PRP & FIN & $\mathrm{CON}$ \\
\hline \multirow{3}{*}{ Big Firms } & KLCI & 1.00 & & & & & & & & & & & \\
\hline & BM100 & $0.99^{\mathrm{a}}$ & 1.00 & & & & & & & & & & \\
\hline & EMAS & $0.99^{\mathrm{a}}$ & $0.99^{\mathrm{a}}$ & 1.00 & & & & & & & & & \\
\hline \multirow{3}{*}{ Small Firms } & BM70 & $0.92^{\mathrm{a}}$ & $0.93^{\mathrm{a}}$ & $0.96^{\mathrm{a}}$ & 1.00 & & & & & & & & \\
\hline & BMSC & $0.85^{\mathrm{a}}$ & $0.85^{\mathrm{a}}$ & $0.90^{\mathrm{a}}$ & $0.95^{\mathrm{a}}$ & 1.00 & & & & & & & \\
\hline & BMFL & $0.79^{a}$ & $0.79^{a}$ & $0.85^{\mathrm{a}}$ & $0.90^{\mathrm{a}}$ & $0.95^{\mathrm{a}}$ & 1.00 & & & & & & \\
\hline \multirow{3}{*}{$\begin{array}{l}\text { Defensive } \\
\text { Industries }\end{array}$} & CSU & $0.89^{\mathrm{a}}$ & $0.88^{\mathrm{a}}$ & $0.90^{\mathrm{a}}$ & $0.90^{\mathrm{a}}$ & $0.85^{\mathrm{a}}$ & $0.82^{\mathrm{a}}$ & 1.00 & & & & & \\
\hline & PLN & $0.77^{\mathrm{a}}$ & $0.76^{\mathrm{a}}$ & $0.77^{\mathrm{a}}$ & $0.77^{\mathrm{a}}$ & $0.73^{a}$ & $0.68^{a}$ & $0.78^{a}$ & 1.00 & & & & \\
\hline & SER & $0.98^{a}$ & $0.98^{a}$ & $0.97^{\mathrm{a}}$ & $0.89^{a}$ & $0.82^{a}$ & $0.76^{a}$ & $0.85^{\mathrm{a}}$ & $0.71^{\mathrm{a}}$ & 1.00 & & & \\
\hline \multirow{3}{*}{$\begin{array}{l}\text { Speculative } \\
\text { Industries }\end{array}$} & PRP & $0.84^{\mathrm{a}}$ & $0.85^{\mathrm{a}}$ & $0.89^{\mathrm{a}}$ & $0.95^{\mathrm{a}}$ & $0.97^{\mathrm{a}}$ & $0.92^{\mathrm{a}}$ & $0.84^{\mathrm{a}}$ & $0.70^{\mathrm{a}}$ & $0.81^{\mathrm{a}}$ & 1.00 & & \\
\hline & FIN & $0.93^{\mathrm{a}}$ & $0.94^{\mathrm{a}}$ & $0.96^{\mathrm{a}}$ & $0.93^{\mathrm{a}}$ & $0.89^{\mathrm{a}}$ & $0.85^{\mathrm{a}}$ & $0.84^{\mathrm{a}}$ & $0.65^{\mathrm{a}}$ & $0.89^{\mathrm{a}}$ & $0.89^{a}$ & 1.00 & \\
\hline & $\mathrm{CON}$ & $0.88^{a}$ & $0.89^{a}$ & $0.92^{\mathrm{a}}$ & $0.94^{\mathrm{a}}$ & $0.90^{\mathrm{a}}$ & $0.85^{\mathrm{a}}$ & $0.81^{\mathrm{a}}$ & $0.66^{\mathrm{a}}$ & $0.85^{\mathrm{a}}$ & $0.90^{\mathrm{a}}$ & $0.92^{\mathrm{a}}$ & 1.00 \\
\hline \multirow{3}{*}{$\begin{array}{l}\text { Sentiment } \\
\text { (Average) }\end{array}$} & CSI & $0.14^{\mathrm{b}}$ & $0.15^{\mathrm{b}}$ & $0.15^{\mathrm{b}}$ & $0.15^{\mathrm{b}}$ & $0.17^{\mathrm{a}}$ & $0.15^{\mathrm{b}}$ & 0.10 & 0.01 & $0.14^{b}$ & $0.20^{\mathrm{a}}$ & $0.18^{\mathrm{a}}$ & $0.16^{\mathrm{b}}$ \\
\hline & BCS & $0.27^{\mathrm{a}}$ & $0.27^{\mathrm{a}}$ & $0.28^{a}$ & $0.29^{a}$ & $0.30^{\mathrm{a}}$ & $0.25^{\mathrm{a}}$ & $0.22^{\mathrm{a}}$ & $0.18^{a}$ & $0.25^{\mathrm{a}}$ & $0.29^{a}$ & $0.28^{a}$ & $0.24^{\mathrm{a}}$ \\
\hline & & & $(0.20)$ & & & $(0.20)$ & & & $(0.16)$ & & & $(0.20)$ & \\
\hline \multirow{4}{*}{$\begin{array}{c}\text { Sentiment } \\
\text { (Positive) }\end{array}$} & CSI+ & $0.13^{\mathrm{b}}$ & $0.14^{\mathrm{b}}$ & $0.15^{b}$ & $0.16^{b}$ & $0.15^{\mathrm{b}}$ & $0.17^{\mathrm{a}}$ & 0.11 & 0.06 & $0.11^{\mathrm{c}}$ & $0.15^{\mathrm{b}}$ & $\mathbf{0 . 1 8}^{\mathrm{a}}$ & $0.15^{\mathrm{b}}$ \\
\hline & BCS+ & $0.21^{\mathrm{a}}$ & $0.21^{\mathrm{a}}$ & $0.20^{\mathrm{a}}$ & $0.19^{a}$ & $0.16^{\mathrm{b}}$ & $0.13^{b}$ & $0.18^{a}$ & $0.14^{b}$ & $0.19^{a}$ & $0.18^{a}$ & $0.21^{\mathrm{a}}$ & $0.17^{\mathrm{a}}$ \\
\hline & FKLI+ & $0.13^{b}$ & $0.14^{b}$ & $0.14^{b}$ & $0.16^{b}$ & $0.14^{b}$ & $0.14^{b}$ & $0.11^{\mathrm{c}}$ & $0.16^{\mathrm{b}}$ & $0.13^{\mathrm{c}}$ & $0.15^{b}$ & $0.12^{b}$ & $0.16^{b}$ \\
\hline & & & $(0.16)$ & & & $(0.16)$ & & & $(\mathbf{0 . 1 3})$ & & & $(0.16)$ & \\
\hline \multirow{4}{*}{$\begin{array}{l}\text { Sentiment } \\
\text { (Negative) }\end{array}$} & CSI- & $-0.13^{b}$ & $-0.14^{\mathrm{b}}$ & $-0.15^{b}$ & $-0.16^{\mathrm{b}}$ & $-0.15^{\mathrm{b}}$ & $-0.17^{a}$ & -0.11 & -0.06 & $-0.11^{\mathrm{c}}$ & $-0.15^{b}$ & $-0.18^{\mathrm{a}}$ & $-0.15^{b}$ \\
\hline & BCS- & $-0.22^{\mathrm{a}}$ & $-0.22^{a}$ & $-0.22^{\mathrm{a}}$ & $-0.21^{\mathrm{a}}$ & $-0.20^{a}$ & $-0.16^{b}$ & $-0.18^{a}$ & $-0.14^{b}$ & $-0.21^{a}$ & $-0.20^{a}$ & $-0.21^{a}$ & $-0.21^{\mathrm{a}}$ \\
\hline & FKLI- & $-0.13^{b}$ & $-0.14^{b}$ & $-0.14^{b}$ & $-0.16^{\mathrm{b}}$ & $-0.14^{b}$ & $-0.14^{b}$ & $-0.11^{\mathrm{c}}$ & $-0.16^{b}$ & $-0.13^{b}$ & $-0.15^{b}$ & $-0.12^{b}$ & $-0.16^{b}$ \\
\hline & & & $(-0.17)$ & & & $(-0.17)$ & & & $(-0.13)$ & & & $(-0.17)$ & \\
\hline \multirow{4}{*}{$\begin{array}{c}\text { Positive } \\
\text { Sentiment in } \\
\text { Non-Crisis }\end{array}$} & CSI+*NC & $0.20^{\mathrm{a}}$ & $0.20^{\mathrm{a}}$ & $0.21^{a}$ & $0.22^{\mathrm{a}}$ & $0.20^{\mathrm{a}}$ & $0.20^{\mathrm{a}}$ & $0.21^{\mathrm{a}}$ & $0.17^{\mathrm{a}}$ & $0.17^{a}$ & $0.21^{\mathrm{a}}$ & $0.21^{\mathrm{a}}$ & $0.18^{a}$ \\
\hline & $\mathbf{B C S}+* \mathbf{N C}$ & $0.19^{a}$ & $0.19^{\mathrm{a}}$ & $0.19^{a}$ & $0.18^{a}$ & $0.18^{\mathrm{a}}$ & $0.16^{\mathrm{b}}$ & $0.19^{a}$ & $0.15^{b}$ & $0.17^{\mathrm{a}}$ & $0.20^{\mathrm{a}}$ & $0.19^{a}$ & $0.17^{\mathrm{a}}$ \\
\hline & $\begin{array}{l}\mathbf{F K L I}+* \mathbf{N} \\
\mathbf{C}\end{array}$ & $0.17^{a}$ & $0.18^{a}$ & $0.19^{\mathrm{a}}$ & $0.20^{\mathrm{a}}$ & $0.21^{\mathrm{a}}$ & $0.19^{a}$ & $0.16^{\mathrm{b}}$ & $0.17^{\mathrm{a}}$ & $0.16^{\mathrm{b}}$ & $0.23^{a}$ & $0.18^{a}$ & $0.20^{\mathrm{a}}$ \\
\hline & & & $(0.19)$ & & & $(0.19)$ & & & $(0.17)$ & & & $(0.20)$ & \\
\hline $\begin{array}{c}\text { Positive } \\
\text { Sentiment in } \\
\text { Crisis }\end{array}$ & $\mathrm{CSI}+* \mathrm{C}$ & $-0.11^{\mathrm{c}}$ & -0.09 & -0.09 & -0.09 & -0.08 & -0.05 & $-0.16^{\mathrm{b}}$ & $-0.17^{\mathrm{a}}$ & -0.09 & -0.09 & -0.05 & -0.04 \\
\hline \multirow{3}{*}{$\begin{array}{c}\text { Negative } \\
\text { Sentiment } \\
\text { in Non-Crisis }\end{array}$} & CSI-*NC & 0.04 & 0.03 & 0.03 & 0.01 & -0.01 & -0.02 & 0.01 & 0.04 & 0.06 & 0.01 & 0.00 & 0.02 \\
\hline & BCS-*NC & 0.04 & 0.04 & 0.03 & 0.02 & -0.02 & 0.00 & 0.03 & 0.07 & 0.03 & -0.01 & 0.02 & 0.00 \\
\hline & FKLI-*NC & 0.07 & $\begin{array}{r}0.06 \\
(0.04)\end{array}$ & 0.05 & 0.02 & $\begin{array}{r}-0.02 \\
(0.00)\end{array}$ & -0.01 & 0.07 & $\begin{array}{r}0.05 \\
(0.05)\end{array}$ & 0.06 & -0.01 & $\begin{array}{r}0.03 \\
(0.05)\end{array}$ & -0.01 \\
\hline \multirow{4}{*}{$\begin{array}{l}\text { Negative } \\
\text { Sentiment } \\
\text { in Crisis }\end{array}$} & CSI-*C & $-0.25^{a}$ & $-0.25^{\mathrm{a}}$ & $\begin{array}{r}-0.25 \\
a\end{array}$ & $-0.24^{a}$ & $-0.21^{a}$ & $\begin{array}{r}-0.21 \\
a\end{array}$ & $-0.18^{a}$ & $-0.16^{\mathrm{b}}$ & $-0.24^{a}$ & $-0.24^{a}$ & $-0.27^{\mathrm{a}}$ & $-0.26^{a}$ \\
\hline & BCS-*C & $-0.38^{a}$ & $-0.37^{a}$ & $-0.36^{\mathrm{a}}$ & $-0.33^{a}$ & $-0.26^{a}$ & $-0.22^{a}$ & $-0.31^{a}$ & $-0.30^{\mathrm{a}}$ & $-0.35^{a}$ & $-0.29^{a}$ & $-0.34^{\mathrm{a}}$ & $-0.30^{\mathrm{a}}$ \\
\hline & FKLI-*C & $-0.26^{\mathrm{a}}$ & $-0.26^{a}$ & $-0.25^{a}$ & $-0.23^{a}$ & $-0.17^{a}$ & $-0.17^{a}$ & $-0.23^{a}$ & $-0.27^{a}$ & $-0.25^{a}$ & $-0.19^{a}$ & $-0.20^{a}$ & $-0.20^{\mathrm{a}}$ \\
\hline & & & $(-0.29)$ & & & $(-0.23)$ & & & $(-0.25)$ & & & $(-0.25)$ & \\
\hline
\end{tabular}

Notes: The full name for stock market indices are as reported before. The sentiment proxies acronym reads as follows: Consumer sentiment index (CSI), Business Condition Survey (BCS), and Equity Futures Index (FKLI)], positive consumer sentiment index (CSI+), positive business condition survey (BCS+), and positive equity futures index (FKLI+), negative consumer sentiment index (CSI-), negative business condition survey (BCS-), and negative equity futures index (FKLI-). The market states are denoted as non-crisis (NC) and crisis (C) which are predetermined crisis market states as discussed in the data section. All sentiment variables are determined by dummy except for CSI, BCS and FKLI. The figures in parentheses are the average correlation of sentiment on the respective groups of indices. The sign $\left({ }^{\mathrm{a}}\right),\left({ }^{\mathrm{b}}\right)$, and $\left({ }^{\mathrm{c}}\right)$ denotes significant level of $1 \%, 5 \%$, and $10 \%$ respectively. The $t$-statistics are unreported due to space constraints.

The correlation analyses show that sentiment risk association to stock returns is universal but the degree of biasness is heterogeneous on the condition of firm size, nature of industry, sentiment states, and market states. The above correlation analysis reveals both confirmation of the existing evidences and also offers new emerging patterns of sentiment risk heterogeneity roles. The correlation analysis can be summarized as follows. Average sentiment is correlated with all segments of indices groups. Positive sentiment is consistently correlated positively with all segments of stock returns group. Negative sentiment is also consistently correlated negatively with all segments of stock returns group. Positive sentiment in non-crisis market states is also consistently positively correlated with returns and provides a higher effect compared to average 
positive sentiment. In all of the above, sentiment-returns correlations are slightly higher for big firms, small firms and speculative industries. Finally, in negative sentiment during market crisis states, negative sentiment is found to be highly in association with all groups of stock returns more than negative sentiment in normal market states and with notably higher association for big firms.

In the second stage of analysis, we examine the strength of relationship of sentiment variables on stock market indices contemporaneous returns taking into account various sentiment segmentations using both OLS and QR-based methods. The objective for OLS analysis is to see the relationships in average perspectives, while the QR analysis aims to uncover the full spectrum of relationships. As for the QR, we perform analysis on various quantiles from extreme lower to extreme higher (i.e. q. $02 \%$, q. $10 \%$, q. $20 \%$, q.50\%, q.80\%, q. $90 \%$, and q.98\%) data distributions. However in the following Table 3, we report on only the extreme lower quantiles (i.e. q.02 to q10) and extreme upper quantiles (i.e. q.90 to q.98) since results from other quantiles are not consistently significant in all data segments.

In the OLS analyses, no significant consistent predictable pattern of sentiment risk associations with stock returns was noted. On the other hand, the QR analyses reveal interesting emerging patterns of sentiment risk asymmetry and heterogeneity roles. Sentiment risk asymetry means that the sentiment and return relations reveal an asymmetric structure of U-curve pattern with a negative magnitude in extreme lower quantile (i.e. within 10\%) to positive magnitude in extreme upper quantiles (within 10\%). This evidence can be theoretically corroborated with the prospect theory which postulates that investors make decisions in reference to risk and returns. This theory also provides theoretical underpinnings for the negative linear relationship of sentiment and returns in extreme lower quantiles and positive linear reationship between them in extreme upper quantiles. These findings can be corroborated with evidence of asymmetry of riskreturn relationship in stock market studies where the slope of relationship changes across the quantiles moving from positive to negative based on QR perspectives (see Chan and Lakonishok, 1992; Allen, Powell and Singh, 2011; Chiang and Li, 2012; Allen, Singh and Powell, 2013; Atkins and Ng, 2014). These evidences have both academic and practical merits. The findings of this study challenge the modern finance assumptions of positive linear relationships between risk and returns, which does not describe reality well and possibly cause wrong risk measurement and management, which in turn may lead to losses and disasters in the stock markets.

In the heterogeneity roles, we observe consistent significant patterns of sentiment-return relationships heterogeneity across four segments of sentiments conditional, i.e. average sentiment, positive sentiment states, negative sentiment states, and negative sentiment states during stock market crisis. First, in average sentiment data perspectives, sentiments are positively significant in affecting the extreme upper quantiles returns for all stock returns segmentations with notable higher degree of biasness for small firms and speculative industries. The fact that small firms are more affected by sentiment risk is in line with existing established evidences (see Baker and Wurgler, 2006; 2007; Lemmon and Portniaguina, 2006; Kaplanski and Levy, 2010). The idea that sentiment plays a bigger role in influencing speculative industries compared to defensive industries is in line with our theoretical postulates and support is provided by a close comparative study provided by Kaplanski and Levy (2010) that states that a less stable industry is more influenced by sentiment compared to a stable industry. Second, in positive 
sentiment states, sentiment proxies consistently have significant positive relation to returns only in extreme upper quantiles with a higher degree of biasness for big firms and speculative industries. These findings can be inferred to popular stock hypothesis postulated in Statman et. al. (2008). Third, in negative sentiment states, negative sentiments negatively induce stock returns only in extreme lower quantiles. To the best of our knowledge, this is a new evidence in sentiment literature. When comparing positive and negative sentiment impacts, the degree of biasness of negative sentiments are higher compared to the positive ones. This is consistent with negativity biases hypothesis highlighted in Akhtar et al. (2011) study. Fourth, in negative sentiment states during stock market crisis condition, two of the sentiment proxies (i.e. CSI and BCS) are consistently significant in negatively affecting the returns of small firms and speculative industries in extreme lower quantiles. In addition, the degree of negative sentiment biases is higher during crisis compared to non-crisis times. This is also, to the best of our knowledge, a new evidence in sentiment literature. This can be corroborated with evidences of the higher negative emotions of retail (Hoffmann, Post, and Pennings, 2013) and professional (Cohn, Fehr and Marechal, 2012) investors during financial crises. In our case, we interpret this as that the impact of negativity bias is stronger given the negative sentiment due to negative opinions coupled with negative emotion due to financial crises.

Table 4: Summary of regression results

\begin{tabular}{|c|c|c|c|c|c|c|c|c|c|c|c|c|}
\hline \multirow{3}{*}{ Segmentations } & \multicolumn{3}{|c|}{$\begin{array}{c}\text { Big Firms } \\
{[\mathrm{KLCI}, \mathrm{BM} 100, \text { EMAS] }}\end{array}$} & \multicolumn{3}{|c|}{$\begin{array}{c}\text { Small Firms } \\
{[\mathrm{BM} 70, \mathrm{BMSC}, \mathrm{BMFL}]}\end{array}$} & \multicolumn{3}{|c|}{$\begin{array}{c}\text { Defensive Industry } \\
{[C S U, \text { PLN, SER] }}\end{array}$} & \multicolumn{3}{|c|}{$\begin{array}{l}\text { Speculative Industry } \\
{[\mathrm{PRP}, \mathrm{FIN}, \mathrm{CON}]}\end{array}$} \\
\hline & \multirow[t]{2}{*}{ OLS } & \multicolumn{2}{|c|}{$\mathrm{QR}$} & \multirow[t]{2}{*}{ OLS } & \multicolumn{2}{|c|}{$\mathrm{QR}$} & \multirow[t]{2}{*}{ OLS } & \multicolumn{2}{|c|}{$\mathrm{QR}$} & \multirow[t]{2}{*}{ OLS } & \multicolumn{2}{|c|}{ QR } \\
\hline & & $\mathrm{L}$ & $\mathrm{H}$ & & $\mathrm{L}$ & $\mathrm{H}$ & & $\mathrm{L}$ & $\mathrm{H}$ & & $\mathrm{L}$ & $\mathrm{H}$ \\
\hline \multicolumn{13}{|l|}{ Average Sentiment } \\
\hline Sentiment-Return Relations & 0 & - & + & 0 & - & + & 0 & - & + & 0 & - & + \\
\hline \multicolumn{13}{|l|}{ Significance } \\
\hline $\mathrm{R}_{\mathrm{t}-1}$ & 0 & + & - & 0 & - & + & - & - & 0 & 0 & - & 0 \\
\hline CSI & 0 & + & + & 0 & + & 0 & 0 & + & + & 0 & + & $+/-$ \\
\hline BCS & + & + & + & + & + & + & + & + & + & + & - & + \\
\hline FKLI & 0 & $+/-$ & + & 0 & + & 0 & + & + & - & + & + & - \\
\hline Strength $(\%)$ & 9.2 & 20.1 & 15.7 & 9.3 & 19.2 & 16 & 7.3 & 16.5 & 9.5 & 9.3 & 20.7 & 16.5 \\
\hline \multicolumn{13}{|l|}{ Positive Sentiment } \\
\hline Sentiment-Return Relations & - & - & + & - & - & + & 0 & - & + & - & - & + \\
\hline \multicolumn{13}{|l|}{ Significance } \\
\hline $\mathrm{R}_{\mathrm{t}-1}$ & + & + & 0 & 0 & + & 0 & 0 & + & - & 0 & + & - \\
\hline CSI+ & 0 & 0 & + & + & + & + & 0 & - & + & + & + & + \\
\hline $\mathrm{BCS}+$ & + & + & + & + & + & + & + & + & + & + & + & + \\
\hline FKLI+ & 0 & + & - & 0 & + & 0 & 0 & + & - & + & + & + \\
\hline Strength $(\%)$ & 6.6 & 20.4 & 13.6 & 5.7 & 16.9 & 10.3 & 4.4 & 16.2 & 9.6 & 6.3 & 18.8 & 13.6 \\
\hline \multicolumn{13}{|l|}{ Negative Sentiment } \\
\hline Sentiment-Return Relations & + & - & + & + & - & + & + & - & + & + & - & + \\
\hline \multicolumn{13}{|l|}{ Significance } \\
\hline $\mathrm{R}_{\mathrm{t}-1}$ & 0 & 0 & 0 & 0 & + & 0 & 0 & + & 0 & 0 & + & $+/-$ \\
\hline CSI- & - & 0 & - & - & - & - & 0 & + & - & - & - & - \\
\hline BCS- & - & - & - & - & - & - & - & - & - & - & - & - \\
\hline FKLI- & 0 & - & 0 & 0 & - & + & 0 & - & + & - & - & 0 \\
\hline Strength $(\%)$ & 7.6 & 20.3 & 13.8 & 6.8 & 16.8 & 12.9 & 4.9 & 16.1 & 10.1 & 7.6 & 18.6 & 15.7 \\
\hline \multicolumn{13}{|c|}{ Positive Sentiment in Non-Crisis } \\
\hline Sentiment-Return Relations & - & - & + & - & - & + & - & - & + & - & - & + \\
\hline \multicolumn{13}{|l|}{ Significance } \\
\hline $\mathrm{R}_{\mathrm{t}-1}$ & 0 & + & - & 0 & + & - & 0 & + & 0 & 0 & + & - \\
\hline $\mathrm{CSI}+* \mathrm{NC}$ & + & - & + & + & + & + & + & - & + & + & 0 & + \\
\hline $\mathrm{BCS}+* \mathrm{NC}$ & 0 & + & 0 & 0 & + & 0 & 0 & + & 0 & 0 & + & 0 \\
\hline FKLI+*NC & 0 & + & 0 & 0 & + & 0 & 0 & + & - & + & + & 0 \\
\hline Strength $(\%)$ & 6.9 & 24.2 & 9.3 & 6.9 & 18.4 & 7.1 & 5.3 & 17.7 & 6.5 & 7.1 & 20.8 & 16.7 \\
\hline \multicolumn{13}{|l|}{ Positive Sentiment in Crisis } \\
\hline Sentiment-Return Relations & 0 & - & + & 0 & - & + & 0 & - & + & 0 & - & + \\
\hline \multicolumn{13}{|l|}{ Significance } \\
\hline $\mathrm{R}_{\mathrm{t}-1}$ & + & + & + & + & + & + & + & + & $+1-$ & + & + & + \\
\hline
\end{tabular}




\begin{tabular}{|c|c|c|c|c|c|c|c|c|c|c|c|c|}
\hline $\mathrm{CSI}+{ }^{*} \mathrm{C}$ & 0 & 0 & 0 & 0 & + & - & - & - & - & 0 & + & 0 \\
\hline $\mathrm{BCS}+{ }^{*} \mathrm{C}$ & + & 0 & + & + & 0 & + & 0 & 0 & + & + & 0 & + \\
\hline $\mathrm{FKLI}+* \mathrm{C}$ & - & - & 0 & - & - & - & - & - & 0 & - & - & - \\
\hline Strength $(\%)$ & 6.9 & 23.4 & 16.7 & 5.1 & 14.5 & 9 & 4.8 & 17.7 & 6.5 & 5.7 & 15.4 & 13.1 \\
\hline \multicolumn{13}{|c|}{ Negative Sentiment in Non-Crisis } \\
\hline Sentiment-Return Relations & - & - & + & - & - & + & - & - & + & - & - & + \\
\hline \multicolumn{13}{|l|}{ Significance } \\
\hline $\mathrm{R}_{\mathrm{t}-1}$ & + & + & 0 & + & + & - & + & + & 0 & + & + & - \\
\hline CSI-*NC & 0 & + & - & 0 & + & - & 0 & + & - & 0 & + & - \\
\hline BCS-*NC & 0 & + & - & 0 & + & - & 0 & 0 & - & 0 & + & - \\
\hline FKLI-*NC & + & + & 0 & 0 & + & - & 0 & + & 0 & 0 & + & - \\
\hline Strength $(\%)$ & 4.4 & 22.2 & 16.7 & 2.9 & 16.7 & 12.5 & 2.9 & 16.8 & 7.7 & 2.5 & 16.7 & 14.3 \\
\hline \multicolumn{13}{|l|}{ Negative Sentiment in Crisis } \\
\hline Sentiment-Return Relations & + & - & + & + & - & + & + & - & + & + & - & + \\
\hline \multicolumn{13}{|l|}{ Significance } \\
\hline $\mathrm{R}_{\mathrm{t}-1}$ & 0 & + & + & + & + & - & 0 & + & - & + & + & + \\
\hline $\mathrm{CSI}-* \mathrm{C}$ & 0 & 0 & 0 & 0 & - & 0 & 0 & + & 0 & - & - & 0 \\
\hline BCS-*C & - & - & - & - & - & - & - & - & - & - & - & - \\
\hline FKLI-*C & 0 & - & + & 0 & 0 & 0 & 0 & - & - & 0 & 0 & + \\
\hline Strength (\%) & 14.5 & 35.1 & 8.6 & 9.3 & 28.6 & 16.7 & 10.9 & 31.1 & 5.1 & 11.7 & 32.4 & 11.7 \\
\hline
\end{tabular}

\section{SYNTHESES OF FINDINGS TO EMPIRICAL, THEORY, AND PRACTICE}

In this section, we discuss our findings in relation to the existing evidences and theory as well as possible investment practical applications.

\subsection{Confirmation, contradiction and emerging findings}

The impact of sentiment depends on market states. This finding is in conformation with the comparative study conducted by Kurov (2010) that noted that monetary policy shock have a strong impact on investor sentiment in bear market conditions and the study by Gracia (2013) that states that sentiment shock is concentrated during a recession. In addition, the findings are also in line with the study by Chung, Hung and Yeh (2012) which provide evidence of insignificant predictive power of average sentiment during a recession. However, complementary to the existing studies, we offer a different interpretation of this situation. In our case, we interpret this to be that the impact of negativity bias is stronger given the negative sentiment due to negative opinions coupled with negative emotion due to financial crises. This opinion can be corroborated with the following findings. First, negative emotion is associated with pessimism (Johnson and Tversky, 1983) in the presence of threatening situations. Second, financial crisis trigger negative emotions and reduce investor risk taking substantially (Cohn, Fehr and Marechal, 2012). Third, fear, which is a negative emotion, arises in the presence of potential danger and induced riskaverse behavior (Lee and Andrade, 2015). These evidences can be inferred to four taxanomies of negativity bias (i.e. negative potency, greater stepness of negative gradients, negativity dominance, and greater negative differentiation) highlighted in Rozin and Royzman (2001) which hypothesizes that even the negative effect is also heterogeneous due to certain situations.

In addition to confirmation on the Western perspective that sentiment risk is higher for small and speculative stocks, this Asian-based research further provides evidence that big firms are also affected by sentiment risk. We linked this finding to the evidence provided by Statman, Fisher and Anginer (2008) which argued that investor attention to admired companies with positive affect characteristics may play a role in influencing demand for a stock. In our case, the big firms indices comprise the top 100 blue chips and medium-size firms. They are popular among investors due to perceived higher potential gains. One 
interesting insight from this finding is that if these big stocks are dominated by institutional investors, the evidence that sentiment is significantly related to this group of stock returns points to the idea that institutional investors are also subjected to sentiment risk - and not only the retail investors as per current belief.

\subsection{Behavioral asset-pricing theory and models}

In line with other behavioral finance scholars' opinion, we also believe that sentiment is one of the systematic risks in asset pricing modeling which cannot be arbitraged away. In behavioral asset pricing modeling, this research provides the following insights that might be valuable for consideration in future discourse. First, sentiment risk influence on stock returns is not homogeneous across different firm size, different industries, sentiment states, and market conditions. Second, sentiment risk and return relationship is homogeneously positive but negative on the extreme lower quantiles (losses) and positive in the extreme upper quantiles (gains) of data distribution. This is in line with the prospect theory perspective. Thus, in behavioral asset pricing modeling and testing, this issue has to be taken into account as average perspective does not provide significant predictive ability of sentiment risk.

\subsection{Behavioral portfolio management strategies}

In investment practice, understanding sentiment risk is important in portfolio risk management particularly in market timing, portfolio allocation, and portfolio rebalancing strategies. In market timing, our analyses show the following: positive sentiment affects more the winners (extreme upper quantiles) of big firms and speculative industries; negative sentiment affects more the losers (extreme lower quantiles) of big firms and speculative industries; positive sentiment during crisis significantly influences the winners (extreme upper quantiles) of big firms and speculative industries; and negative sentiment during crisis significantly influences the winners (extreme upper quantiles) of big firms and speculative industries. All other conditions are not consistently significant. In portfolio allocation, the above findings imply that a balance allocation between big-speculative and small-defensive stocks would be able to minimise the sentiment risk effect on the portfolio. In portfolio rebalancing, a possible strategy arising from insights drawn in this paper are as follows. During positive sentiments, winner stock prices will drop due to selling pressure motivated by profit taking. For negative sentiment, extreme lower return stocks in the portfolio will be pressured downward further due to panic selling or cut-loss motives. Similar conclusion is drawn for positive and negative sentiments during crisis. Equity portfolio managers could capitalise on this by selling winner stocks before heavy selling pressure occurs. The extreme loser stocks in the portfolio can be sold before others and be purchased back at the bottom for a cheaper cost, while stocks in the middle range of quantiles can be held as they are expected to be less vulnerable to sentiment swings.

\section{CONCLUSIONS}

To recap, this research is concerned with modeling local proxies for investor sentiments in the Malaysian stock market environment. The proposed proxies namely CSI, BCS, and FKLI respectively represents consumers, businesses, and investors' perceptions of future conditions for consumption, business, and the stock market. These variables collectively point to the opinions of the likelihood of stock market performance in the near future. Intuitively, should investors pay attention to these indicators and incorporate them in their investment decisions, these variables can be considered as sentiment proxies that serve as consensus opinion of certain groups. These sentiment variables induce investor's feeling of optimism if sentiment indices are high and pessimism if sentiment indices are low. 
In this paper, we assess the economic validity of these sentiment proxies using statistical analysis that are complemented with behavioral insights. In statistical analyses, the association relationships between sentiments to returns are examined in both average and full data distribution perspectives. The statistical analysis is supplemented with behavioral perspectives in acknowledging the heterogeneity roles of sentiment in relation to returns given different conditions. This is done in the following ways. First, we supplemented the analyses with segmentations of indices into firm size (i.e. big and small firms) and industry groups (i.e. defensive and speculative). Second, we draw inferences based on different sentiment conditions (i.e. positive and negative) and market conditions (i.e. crisis and non-crisis). The findings provide confirmation to the heterogeneity role of sentiment across different firm sizes and industries. In addition, negative sentiment is also confirmed to be more influential compared to positive sentiment in line with what had been reflected in behavioral finance literature. More importantly, few emerging patterns emerged in the analysis. First, in contradiction to existing beliefs, big firms are also subjected to sentiment risks. Second, when negative sentiment coexists with bad emotion (i.e. in this case during financial crisis), the combined effect to stock returns are stronger compared to negative sentiment given good emotion conditions. Accordingly, this research not only provides extended theoretical inquiry on sentiment theory and modeling but also provides new insights for investment practitioners and policy makers.

We believe that investigation to sentiment heterogeneity roles is still incomplete and more theoretical and empirical work needs to be undertaken to improve our understanding on investor sentiment theory. In this regard, the analysis of this paper can be further extended in the following ways. First, the role of sentiment given the mixture of sentiment states (i.e. mixture of positive and negative opinions) can be further examined. Second, the role of extreme conditions of sentiment proxies changes can be investigated. Third, the sentiment roles in bull and bear market conditions can be studied. Fourth, the role of positive sentiment should be further analysed as it is currently under-researched. Fifth, the validity of the sentiment proxies in relation to individual stocks returns data should be further tested. Sixth, the association of these sentiment proxies in relation to other investment instruments in Malaysia can be examined. Finally, the insights from this study can be replicated to other Asian countries for confirmation and generalization of the new evidences offered in this paper.

\section{Acknowledgement}

This paper is part of a an ongoing Ph.D. (Behavioral Finance) research project currently undertaken by the first author at the School of Management, Universiti Sains Malaysia (USM) under the supervision of Associate Professor Dr. Zamri Ahmad (co-author). We greatly acknowledge financial support provided by USM (RU-PRGS) under account no. 1001/PMGT/846061.

\section{REFERENCES}

Akhtar, S., Faff, R. and Oliver, B. (2011). The asymmetric impact of consumer sentiment announcements on Australian foreign exchange rates. Australian Journal of Management, 36(3), 387-403.

Akhtar, S., Faff, R., Oliver, B. and Subrahmanyam, A. (2012). Stock salience and the asymmetric market effect of consumer sentiment news. Journal of Banking and Finance, 36, 3289-3301.

Allen, D. E., Singh, A. K. and Powell, R. (2013). Analysing the return distributions of Australian stocks: the CAPM, factor models and quantile regressions. Global Business and Economics Review, 15(1), 88-109.

Andriani, P. and McKelvey, B. (2007). Beyond Gaussian average: Redirecting international business and management research toward extreme events and power laws. Journal of International Business Studies, 38, 1212-1230.

Ariff, M., Nassir, A. M. and Mohamad, S. (1998), Stock pricing in Malaysia, Corporate Financial \& Investment Management, Universiti Putra Malaysia Press: Malaysia. 
Arkes, H., Herren, L. and Isen, A. (1988). The role of potential loss in the influence of affect on risk taking behavior. Organization Behavior and Human Decision Processes, 35, 124-140.

Atkins, A. B. and Ng, P. T. (2014). Refining our understanding of beta through quantile regressions. Journal of Risk and Financial Management, 7, 67-79.

Baker, M. and Wurgler, J. (2006). Investor sentiment and the cross-section of stock returns. Journal of Finance, 61, 1645-1680.

Baker, M. and Wurgler, J. (2007). Investor sentiment in the stock market. Journal of Economic Perspectives, 21(2), 129-151.

Barberies, N., Shleifer, A., and Vishny, R. (1998). A model of investor sentiment. Journal of Financial Economics, 49, 307-343.

Becher, D. A., Jensen, G. R. and Mercer, J. M. (2008). Monetary policy indicators as predictors of stock returns. Journal of Financial Research, 31(4), 357-379.

Black, F. (1986). Noise. Journal of Finance, 41(3), 529-543.

Bormann, S. K. (2013). Sentiment indices on financial markets: What do they measure? Economics Discussion Papers No. 2013-58. Kiel Institute for the World Economy.

Bos, T. and Anderson, S. (1988). Consumer sentiments and share price behavior. Journal of Behavioral Economics, 17(2), 113-118.

Burghardt, M. (2011). Retail investor sentiment and behavior: an empirical analysis. Germany: Gabler Verlag.

Carmichael, B. and Coen, A. (2013). Asset pricing with skewed-normal return. Finance Research Letters, $10,50-57$.

Chan, L. K. C. and Lakonishok, J. (1992). Robust measurement of beta risk. Journal of Finance and Quantitative Analysis, 27(2), 265-282.

Chan, W. S. (1993). Disaggregation of annual time-series data to quarterly figures: A comparative study. Journal of Forecasting, 12, 677-688.

Chang, C. Faff, R. W. and Hwang, C. Y. (2012). Local and global sentiment effects and the role of legal, information and trading environments. Available at SSRN: http://dx.doi.org/10.2139/ssrn.1800550 .

Chen, M. P., Chen, P. F. and Lee, C. C. (2013). Asymmetric effects of investor sentiment on industry stock returns: panel data evidence. Emerging Markets Review, 14, 35-54.

Chiang, T. C. and Li, J. (2012). Stock returns and risk: Evidence from quantile regression analysis. Journal of Risk and Financial Management, 5, 20-58.

Chui, A., Titman, S. and Wei, K. (2010). Individualism and momentum around the world. Journal of Finance, 68(1), 361-392.

Chung, S. L., Hung, C. H., and Yeh, C. Y. (2012). When does investor sentiment predict stock returns? Journal of Empirical Finance, 19, 217-240.

Cohn, A., Fehr, E. and Marechal, M. A. (2012). The psychology impact of booms and busts on risk preferences in financial professionals. Working Paper, Department of Economics, University of Zurich.

Cont, R. (2001). Empirical properties of asset returns: Stylized facts and statistical issues. Quantitative Finance, 1, 223-236.

Dash, S. R. and Mahakud, J. (2013). Investor sentiment and stock market return: do industries matter? Journal of Applied Economic Research, 7(3), 315-349.

De Long, J., Shleifer, A, Summers, L. and Waldmann, R. (1990). Noise trader risk in financial markets. Journal of Political Economics, 98, 703-738.

Dirks, F. C. (1958). Recent investment return on industrial stocks. Journal of Finance, 13(3), 370-385.

Dow, S. C. (2011). Cognition, market sentiment and financial instability. Cambridge Journal of Economics, 35, 233-249.

Elden, R. M., Marcus, A. J. and Tehranian, H. (2010). Relative sentiment and stock returns. Financial Analysts Journal, 66(4), 1-13.

Elton, E. J. and Gruber, M. J. (1970). Homogeneous groups and the testing of economic hypotheses. Journal of Financial and Quantitative Analysis, 4, 581-602. 
Elton, E. J. and Gruber, M. J. (1971). Improved forecasting through the design of homogeneous groups. Journal of Business, 44(4), 432-450.

Fisher, K. and Statman, M. (2004). Sentiment, value, and market-timing. Journal of Investing, 10-21.

Fredrickson, B. L. (2001). The role of positive emotions in positive psychology. American Psychology, 56(3), 218-226.

Gordon, M. J. and Shapiro, E. (1956). Capital equipment analysis: The required rate of profit. Management Science, 3, 102-110.

Gracia, D. (2013). Sentiment during recessions. Journal of Finance, 68(3), 1267-1300.

Graham, B. and Dodd, D. (1940). Security analysis, 2nd ed., McGraw-Hill: United States.

Haupt, H. and Petring, V. (2011). Assessing parametric misspecification and heterogeneity in growth regression. Applied Econometrics Letters, 18, 389-394.

Held, J. (2009). Why it is (still) all about sectors - sectors as a tool for asset allocation. Journal of Indexes, 11-17.

Hoffmann, A., Post, T. and Pennings, J. (2013). Individual investor perceptions and behavior during the financial crisis. Journal of Banking and Finance, 37, 60-74.

Huang, C. L. and Goo, Y. J. (2008). Are happy investors likely to be overconfident? Emerging Markets Finance and Trade, 44(4), 33-39.

Johnson, E. J. and Tversky, A. (1983). Affect, generalization, and the perception of risk. Journal of Personality and Social Psychology, 45, 20-31.

Kahneman, D. and Tversky, A. (1979). Prospect theory: an analysis of decision under risk. Econometrica, 47(2), 263-91.

Kanouse, D. E. (1984). Explaining negativity biases in evaluation and choice behavior: Theory and research. Advances in Consumer Research, 11(1), 703-708.

Kaplanski, G. and Levy, H. (2010). Sentment and stock prices: the case of aviation disaster. Journal of Financial Economics, 95, 174-201.

Kaplanski, G., Levy, H., Veld, C. And Veld-Merkoulova, Y. (2015). Do happy people make optimistic investors? Journal of Financial and Quantitative Analysis, 50(1/2), 145-168.

Keynes, J. M. (1936). The general theory of employment, interest, and money. Harcourt Brace and Co.: New York.

Kim, A.K. and Nofsinger, R.J. (2008). Behavioral Finance in Asia. Pacific-Basin Finance Journal, 16, 17.

Koenker, R. (2013). Discussion: Living beyond our means. Statistical Modelling, 13(4), 323-333.

Koenker, R. and Bassett, G. W. (1978). Regression quantiles. Econometrica, 46, 33-50.

Kumar, A. and Lee, C. (2006). Retail investor sentiment and return co-movements. Journal of Finance, 61(5), 2451-2486.

Kurov, A. (2010). Investor sentiment and the stock market's reaction to monetary policy. Journal of Banking and Finance, 34, 139-149.

Lee, C. J. and Andrade, E. B. (2015). Fear, excitement, and financial risk-taking. Cognition and Emotion, 29(1), 178-187.

Lee, C., Shleifer, A. and Thaler, R. (1991). Investor sentiment and the close-end fund puzzle. Journal of Finance, 46, 75 - 109.

Lemmon, M. and Portniaguina, E. (2006). Consumer confidence and asset prices: Some empirical evidence. Review of Financial Studies, 19(4), 1499-1529.

Li, M. (2014). Moving beyond the linear regression model: Advantages of the quantile regression model. Journal of Management, 1-28.

Lyubomirsky, S. and King, L. (2005). The benefits of frequent positive affect: Does happiness lead to success? Psychology Bulletin, 131(6), 803-855.

Martin, J. D. and Klemkosky, R. C. (1976). The effect of homogeneous stock groupings of portfolio risk. Journal of Business, 49(3), 339-349.

Mat Nor, F., Ibrahim, I., and Rashid, M. (2013). Exposure to investor sentiment in Malaysia: services versus manufacturing stocks. Global Business and Economics Anthology , 1. (in press) 
Miao, H. and Peng, W. (2007). Why A-share market volatility is high. China Economic Issues, 4(7), 1-13.

Morck, R., Shleifer, A. and Vishny, R. W. (1990). The stock market and investment: Is the market a sideshow?" Brookings Papers on Economic Activity, 2, 157-215.

Murphy, A. (2012). Biology-induced effects on investor psychology and behavior. International Review of Financial Analysis, 24, 20-25.

Nagy, Z. and Ruban, O. (2011). Does style make the sector. MSCI Applied Research, 1-17.

Nassir, A. M. (2002). Is the KLSE efficient? efficient market hypothesis vs behavioral finance. Universiti Putra Malaysia, 1-27. Available at; http://psasir.upm.edu.my/1120/1/LG_173_S45_S981_no.610001.pdf

Peng, J., Miao, D. and Xiao, W. (2013). Why are gainers more risk seeking. Judgement and Decision Making, 8(2), 150-160.

Pietri, E. S., Fazio, R. H. and Shook, N. J. (2013). Weighting positive versus negative: The fundamental nature of valence asymmetry. Journal of Personality, 81(2), 196-208.

Puth, M. T., Neuhauser, M. and Ruxton, G. D. (2014). Effective use of Pearson's product-moment correlation coefficient. Animal Behavior, 93, 183-189.

Rozin, P. and Royzman, E. B. (2001). Negativity bias, negativity dominance, and contagion. Personality and Social Psychology Review, 5(4), 296-320.

Safa. M. F. and Maroney, N. C. (2012). Bid-ask spread, futures market sentiment and exchange rate returns. Journal of Economic Cooperation and Development, 33(4), 63-85.

Schmeling, M. (2007). Institutional and individual sentiment: Smart money and noise trader risk? International Journal of Forecasting, 23, 127-145.

Shleifer, A. (2000). Inefficient markets: an introduction to behavioral finance. New York: Oxford University Press.

Shleifer, A. and Summers, L. H. (1990). The noise trader approach to finance. Journal of Economic Perspectives, 4(2), 19-33.

Siegrist, M. and Cvetkovich, G. (2001). Better negative than positive? Evidence from a bias for negative information about possible health dangers. Risk Analysis, 21(1), 199-206.

Simon, A., Stefan, F. and Dirk, N. (2015). Do pessimists move asset prices? Evidence from applying prospect theory to news sentiment. SSRN Working Paper No.

Solt, M. E. and Statman, M. (1988). How useful is the sentiment index? Financial Analysts Journal, 44(5), 45-55.

Stambaugh, F.R., Yu, J. and Yuan, Y. (2012). The short of it: investor sentiment and anomalies. Journal of Financial Economics, 104, 288-302.

Statman, M. (2008). Countries and culture in behavioral finance. CFA Institute Conference Proceedings Quarterly, 38-44.

Statman, M., and Weng, J. A. (2010). Investments accross cultures: financial attitudes of ChineseAmericans. Journal of Investment Consulting , 11(1), 37-44.

Statman, M., Fisher, K. and Anginer, D. (2008). Affect in a behavioral asset-pricing model. Financial Analysts Journal, 64(2), 20-29.

Teng, C. C. and Liu, V. W. (2013). The pre-holiday effect and positive emotion in the Taiwan stock market, 1971-2011. Investment Analysts Journal, 77, 35-43.

Tuyon, J. and Ahmad, Z. (2014). Psychoanalysis of investors' irrationality and dynamism in stock market. Proceeding paper, $16^{\text {th }}$ Malaysian Finance Association Conference (MFA2014), Kuala Lumpur, Malaysia.

Tuyon, J., Ahmad, Z. and Matahir, H. (2015). Theorizing and modeling investor sentiment in Malaysian stock market. Unpublish working paper.

Woodside, A. G. (2013). Moving beyong multiple regression analysis to alogarithms: Calling for adoption of a paradigm shift from symmetric to asymmetric thinking in data analysis and crafting theory. Journal of Business Research, 66, 463-472.

Yates, F. J., Lee, J. W. and Bush, J. G. (1997). General knowledge overconfidence: cross-national variations, response style, and "reality". Organizational Behavior and Human Decision Processes, 
70(2), 87-94.

Yu, K. and Stander, J. (2003). Quantile regression: Applications and current research areas. The Statisticians, 52(3), 331-350.

Zapata, H. O., Detre, J. D. and Hanabuchi, T. (2012). Historical performance of commodity and stock markets. Journal of Agricultural and Applied Economics, 44(3), 339-357.

Zouaoui, M., Nouyrigat, G. and Beer, F. (2011). How does investor sentiment affect stock market crises? Evidence from panel data. The Financial Review, 46, 723-747.

Appendices

Table 5a: Regression Tests (Sentiment Average)

\begin{tabular}{|c|c|c|c|c|c|c|c|c|c|c|}
\hline \multirow{2}{*}{ Segmentation } & \multirow{2}{*}{ Indices } & \multirow{2}{*}{ Variables } & \multirow{2}{*}{$\frac{\text { Mean-Based }}{\text { OLS }}$} & \multicolumn{6}{|c|}{ Quantile-Based } & \multirow[b]{2}{*}{ q98 } \\
\hline & & & & $\mathrm{q} 02$ & $\mathrm{q} 10$ & $\mathrm{q} 20$ & $\mathrm{q} 50$ & q80 & q90 & \\
\hline \multirow{18}{*}{ Big Firms } & KLCI & $\mathrm{C}$ & 0.1096 & $-14.4621 * * *$ & $-8.0298 * * *$ & $-4.6959 * * *$ & 0.5093 & $3.9992 * * *$ & $6.7260 * * *$ & $14.795 * * *$ \\
\hline & & $\mathrm{R}_{t-1}$ & 0.4949 & $3.9015^{* * * *}$ & $2.0319^{*}$ & 0.2852 & -0.1442 & 0.6629 & 1.567848 & $-5.3410 * * *$ \\
\hline & & CSI & 0.0830 & $0.8215^{* * *}$ & $0.3163^{*}$ & 0.1034 & 0.0240 & 0.1098 & $0.2260^{* *}$ & 0.1646 \\
\hline & & BCS & $0.2897 * * * *$ & -0.0104 & $0.1878^{*}$ & 0.1886 & 0.1176 & 0.1068 & $0.1637 * *$ & $0.4594 * * *$ \\
\hline & & FKLI & -0.3863 & $-3.2889 * *$ & -1.6662 & 0.1249 & 0.2549 & -0.6647 & -1.5716 & $5.2145^{* * *}$ \\
\hline & & $R^{2}$ & 0.0872 & 0.2512 & 0.1472 & 0.0646 & 0.0130 & 0.0288 & 0.0663 & 0.2400 \\
\hline & BM100 & $\mathrm{C}$ & $0 . \overline{1588}$ & $-13.3853^{* * * *}$ & $-7.9993^{*} * x_{*}$ & $-\overline{4} \overline{4} \overline{4} 9^{* * *}$ & $0 . \overline{5075}$ & $4.2833^{*}$ * & $\overline{7} .0063^{* * *}$ & $16 . \overline{95} 4^{* * * *}$ \\
\hline & & $\mathrm{R}_{t-1}$ & -0.7560 & -1.3648 & -1.2013 & -0.9091 & -0.7091 & -0.2975 & 0.6454 & $-4.1648^{* * *}$ \\
\hline & & CSI & 0.1281 & $0.7938 * * *$ & 0.3432 & 0.1272 & 0.0479 & $0.2016^{*}$ & 0.1612 & $0.9816^{* * *}$ \\
\hline & & BCS & $0.2888^{* * * *}$ & 0.1261 & 0.1132 & 0.1591 & 0.1185 & 0.1393 & 0.2189 & 0.287752 \\
\hline & & FKLI & 0.8768 & 1.8429 & 1.6693 & 1.3250 & 0.8371 & 0.2802 & -0.6459 & $3.7916^{* *}$ \\
\hline & & $R^{2}$ & 0.0946 & 0.2499 & 0.1351 & 0.0677 & 0.0197 & 0.0394 & 0.0712 & 0.2456 \\
\hline & BMEMAS & $\mathrm{C}$ & 0.0519 & $-14.0641^{*} * *$ & 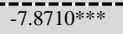 & $-5.0095^{* * *}$ & 0.5272 & $4.2404 * * *$ & $7.3083^{* * *}$ & $16.484 * * *$ \\
\hline & & $\mathrm{R}_{t-1}$ & -0.2382 & $-1.3711 * * *$ & -0.8448 & -0.0307 & -0.1271 & -0.0398 & 0.4698 & -0.5732 \\
\hline & & CSI & 0.1305 & $0.8598 * * *$ & 0.3269 & 0.1063 & 0.0508 & 0.1590 & $0.3757^{* * * *}$ & 0.1406 \\
\hline & & BCS & $0.3088^{* * *}$ & $0.1586^{*}$ & 0.0971 & 0.1425 & 0.1023 & $0.1503^{*}$ & 0.1193 & $0.6257 * *$ \\
\hline & & FKLI & 0.3542 & $1.9319^{* * *}$ & $1.3343^{*}$ & 0.4764 & 0.2682 & 0.0199 & -0.5232 & 0.2780 \\
\hline & & $R^{2}$ & 0.0932 & 0.2975 & 0.1239 & 0.0652 & 0.0198 & 0.0396 & 0.0759 & 0.2433 \\
\hline \multirow{18}{*}{ Small Firms } & BM70 & $\mathrm{C}$ & 0.0003 & $-15.0724 * * *$ & $-9.0797 * * *$ & $-5.6357 * * *$ & $\begin{array}{l}-0.7847 \\
\end{array}$ & 5.4757 **** & $7.2009^{* * *}$ & $18.804^{* * * *}$ \\
\hline & & $\mathrm{R}_{t-1}$ & 0.0235 & $-0.2570^{*}$ & -0.0454 & 0.0569 & 0.1389 & 0.0041 & -0.198188 & -1.0105 \\
\hline & & CSI & 0.1111 & $0.9943 * * *$ & $0.4799 *$ & 0.1450 & 0.7645 & 0.2269 & $0.2359^{*}$ & -0.2985 \\
\hline & & BCS & $0.3798^{* * * *}$ & $0.3161 * * *$ & $0.2916^{*}$ & 0.2588 & 0.5027 & 0.2688 & $0.3201 * *$ & $0.7380 * * *$ \\
\hline & & FKLI & 0.0915 & $0.7478^{* * * *}$ & $0.4771 *$ & 0.3537 & 0.7290 & -0.0269 & 0.1581 & 0.6139 \\
\hline & & $R^{2}$ & 0.0989 & 0.2995 & 0.1397 & 0.0757 & 0.0134 & 0.0383 & 0.0776 & 0.2792 \\
\hline & $\overline{\mathrm{B}} \overline{\mathrm{M}} \overline{\mathrm{C}}$ & $\bar{C}$ & -0.1642 & $-17.229^{*}$ * & $-10.589^{*}$ *** & $-5.8821 * * *$ & $0 . \overline{1298}$ & 5.7139 *水水 & 8.4891 *** & $21.670^{* * *}$ \\
\hline & & $\mathrm{R}_{t-1}$ & 0.0603 & -0.0507 & -0.0694 & 0.0380 & -0.0824 & 0.0839 & 0.1488 & -0.0071 \\
\hline & & CSI & 0.1700 & $1.2290 * * *$ & $0.6244 * *$ & $0.2806^{*}$ & 0.0025 & 0.1162 & 0.1661 & -0.1489 \\
\hline & & BCS & $0.4460^{* * * *}$ & 0.1568 & 0.2380 & 0.1180 & 0.2826 & $0.2802 *$ & $0.3540^{*}$ & $1.0662^{* * * *}$ \\
\hline & & FKLI & 0.0175 & 0.4941 & 0.4210 & $0.3025^{*}$ & 0.1907 & -0.1450 & -0.3391 & -0.2011 \\
\hline & & $R^{2}$ & 0.1009 & 0.2694 & 0.1044 & 0.0614 & 0.0145 & 0.0398 & 0.0686 & 0.2710 \\
\hline & BMFL & $\mathrm{C}$ & -0.174976 & $-19.7087^{*} * *$ & $-11.4872^{*} * *$ & $-5.2428 * * *$ & -0.0025 & $5.0586^{* *}$ & 8.8201 *** & $24.948 * * *$ \\
\hline & & $\mathrm{R}_{t-1}$ & 0.052642 & -0.0148 & $-0.2082 *$ & -0.1050 & -0.0767 & 0.0655 & $0.2908^{* *}$ & 0.1096 \\
\hline & & CSI & 0.191697 & $1.5051 * * *$ & $0.6714 * *$ & $0.3287^{*}$ & 0.0146 & 0.1672 & 0.0172 & 0.0480 \\
\hline & & BCS & $0.3575^{* * * *}$ & 0.0498 & 0.094835 & 0.0537 & 0.0821 & 0.1820 & 0.3619 & $0.9852 * * *$ \\
\hline & & FKLI & 0.091762 & $0.5221^{* *}$ & $0.6295 * * *$ & $0.4013 * * *$ & 0.2385 & 0.0084 & -0.3369 & -0.0248 \\
\hline & & $R^{2}$ & 0.078676 & 0.2575 & 0.0812 & 0.0403 & 0.0114 & 0.0298 & 0.0560 & 0.2069 \\
\hline \multirow{18}{*}{$\begin{array}{l}\text { Defensive } \\
\text { Industries }\end{array}$} & CSU & $\mathrm{C}$ & 0.3910 & $-13.3916^{* *}$ & $-5.6393 * * *$ & $-3.2277 * * *$ & $0.6212 *$ & $3.7062 * * *$ & $5.9691^{* * * *}$ & $10.330^{* * * *}$ \\
\hline & & $\mathrm{R}_{t-1}$ & $-0.2936 * *$ & $-0.7782 * *$ & $-0.4416 * * *$ & -0.4451 & -0.1581 & -0.0987 & 0.0787 & 0.2627 \\
\hline & & CSI & 0.0124 & 0.279885 & $0.2526^{*}$ & 0.0713 & -0.0086 & -0.0420 & 0.1413 & -0.3227 \\
\hline & & BCS & $0.1753^{* *}$ & -0.083489 & -0.0821 & 0.0300 & 0.0301 & $0.1482 *$ & 0.1389 & $0.5671^{* * *}$ \\
\hline & & FKLI & $0.3339 * * *$ & $1.1660^{*}$ & $0.6271^{* * *}$ & $0.5533 * * *$ & $0.2443 *$ & 0.0776 & -0.0971 & $-0.4036 * *$ \\
\hline & & $R^{2}$ & 0.0845 & 0.1842 & 0.1143 & 0.0796 & 0.0160 & 0.0250 & 0.0337 & 0.1827 \\
\hline & $\overline{\mathrm{PLN}}$ & $\mathrm{C}$ & $0.34 \overline{12}$ & $-15.6872^{* * * *}$ & $-7.8083^{*}$ & $-4.4672^{*} \cdot$ & $0 . \overline{782} 4 *$ & $4.83 \overline{3} 4$ * & 8.0022 *** & $12.655^{* * *}$ \\
\hline & & $\mathrm{R}_{t-1}$ & -0.0390 & $0.4229 * * *$ & -0.0800 & 0.0344 & -0.0234 & 0.0947 & -0.0002 & -0.0228 \\
\hline & & CSI & -0.1151 & 0.4272 & $-0.4930^{* * *}$ & -0.0915 & 0.0028 & -0.0653 & 0.1505 & -0.0274 \\
\hline & & BCS & $0.2109^{* *}$ & 0.3662 & $0.4199 * *$ & $0.3259 * *$ & 0.0882 & $0.1929 * *$ & 0.0236 & 0.2904 \\
\hline & & FKLI & 0.1771 & 0.1465 & $0.4737 * * *$ & $0.2927 *$ & 0.1735 & -0.1696 & -0.0723 & -0.2275 \\
\hline & & $R^{2}$ & 0.0535 & 0.2013 & 0.1364 & 0.0521 & 0.0156 & 0.0200 & 0.0206 & 0.0518 \\
\hline & SER & $\mathrm{C}$ & 0.0069 & $-14.7622^{\text {**** }}$ & $-7.2740 * * *$ & $-7.6383^{* * *}$ & 0.5828 & $3.9942^{*} * *$ & 7.3968 *** & $15.198^{* * * *}$ \\
\hline & & $\mathrm{R}_{t-1}$ & -0.2510 & -0.3795 & -0.1740 & 0.080529 & -0.1606 & -0.3127 & -0.3563 & -0.5198 \\
\hline & & CSI & 0.1053 & $0.8369 * * *$ & 0.2690 & 0.075424 & 0.0073 & 0.1767 & $0.3712 * * *$ & 0.3406 \\
\hline & & BCS & $0.2709^{* * * *}$ & -0.0243 & 0.0783 & $2.0704 *$ & 0.0986 & 0.1567 & $0.2639^{* *}$ & $0.6451^{* * * *}$ \\
\hline & & FKLI & 0.3618 & 0.9589 & 0.6572 & $4.1435^{* *}$ & 0.2062 & 0.3102 & 0.2840 & 0.3549 \\
\hline & & $R^{2}$ & 0.0808 & 0.2275 & 0.1286 & 0.0693 & 0.0157 & 0.0303 & 0.0702 & 0.2097 \\
\hline \multirow{5}{*}{$\begin{array}{l}\text { Speculative } \\
\text { Industries }\end{array}$} & PRP & $\mathrm{C}$ & -0.3148 & $-16.911 * * *$ & $-10.0179 * * *$ & $-6.5520 * * *$ & -0.2008 & $5.7490^{* * * *}$ & $8.3515^{* * * *}$ & $19.626^{* * * *}$ \\
\hline & & $\mathrm{R}_{t-1}$ & 0.1414 & -0.0252 & 0.0311 & 0.0982 & 0.0747 & $0.3156^{*}$ & 0.1662 & 0.0567 \\
\hline & & CSI & 0.2340 & $1.0990^{* * *}$ & $0.4749^{*}$ & $0.3381 * *$ & 0.1283 & 0.2234 & $0.3903^{* * *}$ & -0.1985 \\
\hline & & $\mathrm{BCS}$ & $0.3864^{* * * *}$ & 0.1375 & 0.0859 & -0.0295 & 0.2372 & 0.1499 & $0.3583^{* * *}$ & $0.9195^{* * *}$ \\
\hline & & FKLI & -0.0573 & 0.4498 & $0.4044^{* * * *}$ & $0.2879^{*}$ & 0.0700 & $-0.3227 *$ & -0.3131 & -0.3828 \\
\hline
\end{tabular}




\begin{tabular}{|c|c|c|c|c|c|c|c|c|c|}
\hline & $R^{2}$ & 0.1054 & 0.2819 & 0.1218 & 0.0751 & 0.0213 & 0.0510 & 0.0853 & 0.2787 \\
\hline \multirow[t]{5}{*}{ FIN } & $\mathrm{C}$ & 0.1597 & $-19.7215^{* * * *}$ & $-10.0625^{* * *}$ & $-4.6740 * * *$ & $0.9071 *$ & $4.4105^{* * * *}$ & $7.5875^{* * * *}$ & $20.527 * * *$ \\
\hline & $\mathrm{R}_{t-1}$ & 0.1271 & 0.0031 & -0.1375 & 0.3006 & -0.1358 & 0.0279 & 0.2117 & 0.5348 \\
\hline & CSI & 0.1983 & $1.1910^{* * * *}$ & $0.8091 *$ & 0.1540 & 0.1016 & $0.2139^{*}$ & $0.4282^{* * * *}$ & $-1.4898 * *$ \\
\hline & FKLI & -0.0590 & $0.6162 *$ & 0.6265 & -0.0260 & 0.3502 & 0.0863 & -0.2319 & -0.6399 \\
\hline & $R^{2}--$ & 0.0970 & 0.2737 & 0.0969 & 0.0582 & 0.0230 & 0.0423 & 0.0575 & 0.2607 \\
\hline \multirow[t]{5}{*}{$\mathrm{CON}$} & $\mathrm{C}$ & -0.3775 & $-22.0560^{* * * *}$ & $-12.5491 * * *$ & $-6.2913 * * *$ & 0.2852 & $4.9768 * * *$ & $8.2684 * * *$ & $25.560 * * *$ \\
\hline & CSI & 0.2558 & $1.5958 * * *$ & $1.0195 * * *$ & 0.2505 & 0.0552 & 0.0757 & -0.0175 & -0.6134 \\
\hline & BCS & $0.3524 *$ & $-0.6629 * * *$ & 0.1068 & 0.1606 & 0.1482 & 0.3076 & 0.2359 & $1.1943 * * *$ \\
\hline & FKLI & $0.3529 *$ & $2.3506^{* * *}$ & $1.3596^{* * * *}$ & 0.4105 & 0.1730 & 0.2086 & $0.4332^{*}$ & $-0.8331^{*}$ \\
\hline & $R^{2}$ & 0.0766 & 0.3289 & 0.1369 & 0.0590 & 0.0191 & 0.0282 & 0.0353 & 0.2750 \\
\hline
\end{tabular}

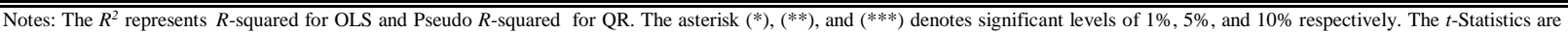
unreported due to space constraint.

Table 5b: Regression Tests (Positive Sentiments)

\begin{tabular}{|c|c|c|c|c|c|c|c|c|c|c|}
\hline \multirow{2}{*}{ Segmentation } & \multirow{2}{*}{ Indices } & \multirow{2}{*}{ Variables } & \multirow{2}{*}{$\begin{array}{c}\text { Mean-Based } \\
\text { OLS }\end{array}$} & \multicolumn{6}{|c|}{ Quantile-Based } & \multirow[b]{2}{*}{ q98 } \\
\hline & & & & $\mathrm{q} 02$ & $\mathrm{q} 10$ & $\mathrm{q} 20$ & $\mathrm{q} 50$ & $\mathrm{q} 80$ & $\mathrm{q} 90$ & \\
\hline \multirow{18}{*}{ Big Firms } & \multirow[t]{6}{*}{ KLCI } & $\mathrm{C}$ & -1.3662 & $-20.9792^{* * * *}$ & $-10.9456^{* * * *}$ & $-7.1956^{* * *}$ & -0.1714 & $3.9207 * * *$ & $6.2395 * * *$ & $17.4551^{*}$ \\
\hline & & $\mathrm{R}_{t-1}$ & $0.1488^{* *}$ & $0.3343 * *$ & 0.2982 & 0.2671 & 0.1622 & $0.1949 * * *$ & 0.0426 & 0.3120 \\
\hline & & CSI+ & 0.8312 & 3.5373 & 0.2897 & 0.7259 & 0.4819 & 1.5233 & $3.8170^{* * *}$ & $5.1465^{* *}$ \\
\hline & & $\mathrm{BCS}+$ & $2.2517 * * *$ & $8.2304 * *$ & 3.0611 & 1.3642 & 0.9073 & 0.2835 & 0.8031 & 9.1951 \\
\hline & & FKLI+ & -0.1466 & 0.2252 & 2.6924 & 2.8167 & -0.1379 & $-1.9861 * *$ & -2.5051 & -13.0629 \\
\hline & & $R^{2}$ & 0.0685 & 0.2633 & 0.1348 & 0.0710 & 0.0185 & 0.0380 & 0.0430 & 0.2315 \\
\hline & \multirow[t]{6}{*}{ BMíno } & $\overline{\mathrm{C}}$ & $-1.6728^{*}$ & $-23.9850^{\text {***.* }}$ & $-11.2144^{* * *}$ & -7.0854 冰* & -0.5203 & $4.1003^{* * *}$ & $6.2832 * * *$ & 15.2975 \\
\hline & & $\mathrm{R}_{t-1}$ & 0.1130 & 0.2077 & 0.2696 & 0.2464 & 0.1136 & 0.1312 & 0.0197 & 0.0324 \\
\hline & & CSI+ & 1.0006 & 0.4190 & 0.3119 & 0.2382 & 0.7895 & $1.8891 *$ & $3.9245^{* *}$ & $5.4643^{*}$ \\
\hline & & $\mathrm{BCS}+$ & $2.2110^{* *}$ & 9.9292* & 2.7682 & 1.1302 & 0.7965 & 0.1556 & 0.4806 & 8.8661 \\
\hline & & FKLI+ & 0.3259 & 4.9210 & 3.8274 & 3.1353 & 0.3060 & -1.9087 & -1.3738 & -9.4640 \\
\hline & & $R^{2}$ & 0.0651 & 0.2819 & 0.1371 & 0.0665 & 0.0211 & 0.0323 & 0.0527 & 0.2172 \\
\hline & \multirow[t]{6}{*}{ BMEMAS } & $\mathrm{C}$ & $-1.8030^{* *}$ & $-22.9242^{\text {**** }}$ & 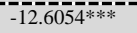 & $-7.0169^{\text {**** }}$ & -0.3728 & $3.5307 * * *$ & $6.5325 * * *$ & $13.134 * * *$ \\
\hline & & $\mathrm{R}_{t-1}$ & 0.113720 & 0.2241 & 0.1157 & $0.3366 * * *$ & 0.0603 & 0.1338 & 0.0428 & 0.014099 \\
\hline & & CSI+ & 1.175041 & 2.0919 & 0.6802 & 0.3859 & 0.6739 & $2.0902 *$ & 3.1989 & $5.9610^{* *}$ \\
\hline & & $\mathrm{BCS}+$ & $2.1075^{* *}$ & $9.1655 * *$ & 2.9496 & 1.5903 & 0.6098 & 0.1127 & -0.1820 & $10.5897 * *$ \\
\hline & & FKLI+ & 0.366852 & 2.0270 & $5.2088 * *$ & 2.2062 & 0.5358 & -1.3194 & -0.9934 & $-7.2540^{* *}$ \\
\hline & & $R^{2}$ & 0.064488 & 0.2773 & 0.1293 & 0.0482 & 0.0214 & 0.0311 & 0.0496 & 0.2245 \\
\hline \multirow{18}{*}{ Small Firms } & \multirow[t]{6}{*}{ BM70 } & $\mathrm{C}$ & $-2.3233^{*} *$ & $-24.8246^{* * * *}$ & $-12.5853^{* * * *}$ & $-9.3226 * * *$ & -0.7847 & $4.1055^{* * *}$ & $5.2114 * * *$ & $7.6426^{* * *}$ \\
\hline & & $\mathrm{R}_{t-1}$ & 0.1007 & $0.2530^{* *}$ & 0.2311 & $0.2535^{* *}$ & 0.1389 & 0.0856 & -0.0085 & -0.1737 \\
\hline & & CSI+ & 1.5274 & 4.6787 & -0.2583 & 1.4144 & 0.7645 & $2.5714^{*}$ & $5.0506^{* * * *}$ & 2.4821 \\
\hline & & $\mathrm{BCS}+$ & $2.0600^{* * *}$ & $9.0701 * *$ & 2.4400 & 1.7140 & 0.5027 & 0.7244 & -0.5797 & $15.4086 * *$ \\
\hline & & FKLI+ & 0.9306 & 0.148086 & $5.0067 * *$ & $3.6889^{*}$ & 0.7290 & -1.2817 & -0.3147 & 1.7578 \\
\hline & & $R^{2}$ & 0.0652 & 0.2720 & 0.1312 & 0.0739 & 0.0134 & 0.0404 & 0.0710 & 0.2135 \\
\hline & \multirow[t]{6}{*}{$\mathrm{BMSC}$} & $\mathrm{C}$ & $-2.6703^{*} *$ & $-25.6383^{\text {**** }}$ & $-16.4001^{* * *}$ & $-10.2323^{* * *}$ & $-2.3334^{*}$ & $4.2499 * * *$ & $7.2939 * * *$ & $15.675^{*} * *$ \\
\hline & & $\mathrm{R}_{t-1}$ & 0.0782 & $0.3112 * * *$ & 0.0274 & 0.0920 & 0.0296 & 0.0590 & 0.0978 & -0.3597 \\
\hline & & CSI+ & 1.9176 & $10.5193 * * *$ & 3.4896* & 1.6487 & 1.4371 & 2.3986 & 2.3753 & -5.5793 \\
\hline & & $\mathrm{BCS}+$ & 1.7242 & $5.1059 * *$ & 1.2441 & $2.7053^{*}$ & 0.7729 & -1.5278 & -0.7439 & $15.4869 * *$ \\
\hline & & FKLI+ & 1.1885 & -3.7757 & $6.7568 * * *$ & 3.6542 & 1.7745 & 1.3111 & -1.0362 & 5.7480 \\
\hline & & $R^{2}$ & 0.0517 & 0.2408 & 0.0942 & 0.0611 & 0.0119 & 0.0202 & 0.0218 & 0.1307 \\
\hline & $\overline{\mathrm{BMFL}}$ & $\mathrm{C}$ & $-2.7844^{*} *$ & $-34.4495^{* * * *}$ & $-15.4833^{* * *}$ & $-7.8078^{\text {**** }}$ & $-2.4477^{* *}$ & $4.1813^{*}{ }^{*} *$ & $7.9229^{* * *}$ & $14.145^{* * *}$ \\
\hline & & $\mathrm{R}_{t-l}$ & 0.0869 & $0.3653^{* * *}$ & 0.0916 & 0.022123 & 0.0068 & 0.1005 & 0.1159 & 0.2812 \\
\hline & & CSI+ & $2.7155^{*}$ & $15.0393 * * *$ & 3.7052 & $2.7967 *$ & 1.4216 & $3.1234 *$ & 1.9237 & 3.3860 \\
\hline & & $\mathrm{BCS}+$ & 0.9633 & 3.9489 & -0.7210 & -0.3597 & 0.2312 & -0.9929 & 0.7522 & $18.516^{* *}$ \\
\hline & & FKLI+ & 1.3059 & 0.6986 & $5.6974 *$ & 2.6832 & $2.6730 * *$ & 0.0124 & -0.9869 & 1.0175 \\
\hline & & $R^{2}$ & 0.0529 & 0.2207 & 0.0541 & 0.0311 & 0.0213 & 0.0317 & 0.0263 & 0.1575 \\
\hline & $\overline{\mathrm{CSU}}$ & $\mathrm{C}$ & -1.0952 & $-25.6753^{* * * *}$ & $-8.5147 * * *$ & $-5.0920^{* * *}$ & 0.227898 & $2.8291 * * *$ & $5.1871^{* * *}$ & $6.8213^{* * *}$ \\
\hline & & $\mathrm{R}_{t-1}$ & 0.0462 & -0.228755 & 0.0493 & -0.1098 & -0.0001 & -0.0266 & 0.0667 & 0.1313 \\
\hline & & CSI+ & 0.6319 & $-3.1889 *$ & 1.4284 & 0.3621 & -0.0265 & 1.2942 & $2.1953 * *$ & $3.0820 * *$ \\
\hline & & $\mathrm{BCS}+$ & $1.5738^{*}$ & $9.5602 *$ & -0.2189 & 1.4478 & 0.5105 & 1.3688 & 0.4469 & $14.838^{*}$ \\
\hline & & FKLI+ & 0.5355 & $12.3408^{* *}$ & $3.5949 * *$ & $2.4914 * *$ & 0.5366 & -0.3658 & $-1.7170^{*}$ & $-3.1678^{*}$ \\
\hline & & $R^{2}$ & 0.0398 & 0.1867 & 0.0619 & 0.0306 & 0.0065 & 0.0291 & 0.0552 & 0.1891 \\
\hline & PLN & $\mathrm{C}$ & -1.3111 & $-23.0451^{* * * *}$ & $-12.4947^{* * * *}$ & $-6.8434 * * *$ & -0.6481 & 5.0239 *** & $8.1452^{* * *}$ & $12.156^{* * *}$ \\
\hline & & $\mathrm{R}_{t-1}$ & 0.0551 & $0.4602 * *$ & 0.0092 & 0.1419 & 0.0441 & 0.0804 & 0.0022 & $-0.2731^{*}$ \\
\hline Defensive & & CSI+ & 0.3029 & 0.0152 & -1.0415 & -0.4847 & 1.3891 & 0.2989 & 0.9626 & -1.5195 \\
\hline Industries & & $\mathrm{BCS}+$ & 1.4684 & 6.8818 & 2.5338 & 1.2686 & 0.0817 & 1.0506 & 1.2566 & 1.9375 \\
\hline & & FKLI+ & 1.4001 & 4.6745 & $6.1283^{*}$ & $3.4988^{*}$ & 1.1156 & -1.4361 & -2.4716 & 2.1998 \\
\hline & & $R^{2}$ & 0.0378 & 0.2404 & 0.1049 & 0.0422 & 0.0185 & 0.0142 & 0.0317 & 0.0533 \\
\hline & SER & $\mathrm{C}$ & $-\overline{1.5138}$ & $-21.4974^{* * * *}$ & $-12.0240^{\text {**** }}$ & $-7.6383^{*}$ ** & -0.0880 & $3.9435 * * *$ & $8.5841^{*} * *$ & $17.664^{*}$ \\
\hline & & $\mathrm{R}_{t-1}$ & 0.1119 & 0.4696 & 0.0893 & 0.0805 & 0.1551 & 0.1823 & 0.0939 & 0.2237 \\
\hline & & $\mathrm{CSI}+$ & 0.6328 & 2.1139 & 0.3828 & 0.0754 & 0.4342 & 1.4290 & 2.7733 & $4.6474 * *$ \\
\hline & & $\mathrm{BCS}+$ & $2.1711^{* *}$ & 7.8793* & 2.4259 & $2.0704 *$ & 0.9216 & -0.3760 & 0.8781 & 7.2884 \\
\hline & & FKLI+ & 0.2499 & -0.3029 & $5.5263^{* * *}$ & $4.1435^{* *}$ & -0.4776 & -1.6755 & -3.8293 & -12.1396 \\
\hline & & $R^{2}$ & 0.0541 & 0.2465 & 0.1326 & 0.0693 & 0.0129 & 0.0159 & 0.0415 & 0.2068 \\
\hline & PRP & $\mathrm{C}$ & $-2.6806^{* *}$ & $-25.0205^{* * * *}$ & $-15.3936^{* * * *}$ & $-9.8949 * * *$ & -1.9102 & $4.0073 * * *$ & $5.8591 * * *$ & $12.960 * * *$ \\
\hline & & $\mathrm{R}_{t-1}$ & 0.114821 & $0.3189 * * *$ & 0.1570 & $0.1717^{*}$ & 0.0618 & 0.0752 & 0.1280 & $-0.6009 * *$ \\
\hline $\begin{array}{l}\text { Speculative } \\
\text { Industries }\end{array}$ & & CSI+ & 1.744681 & $10.2581 * * *$ & 2.2104 & 1.7535 & 0.6178 & $2.8142^{*}$ & 1.7408 & -4.6552 \\
\hline & & $\mathrm{BCS}+$ & 1.893601 & $4.7304 * *$ & 3.0288 & 0.7379 & 1.1561 & 0.3836 & 1.4121 & $12.202 * *$ \\
\hline & & FKLI+ & 0.866304 & -2.1285 & 3.9202 & $3.8847^{*}$ & 1.7838 & -0.6012 & -0.0249 & 10.4335 \\
\hline
\end{tabular}




\begin{tabular}{|c|c|c|c|c|c|c|c|c|c|}
\hline & $R^{2}$ & 0.061973 & 0.2757 & 0.1000 & 0.0755 & 0.0181 & 0.0360 & 0.0367 & 0.1761 \\
\hline \multirow[t]{4}{*}{ FIN } & $\mathrm{C}$ & $-2.3955^{*}$ & $-29.7811^{* * * *}$ & $-16.2212^{* * *}$ & $-5.8921 * * *$ & -0.6464 & $3.2684 * * *$ & $6.4244 * * *$ & $11.383^{* * *}$ \\
\hline & CSI+ & $2.1374 *$ & $11.25734^{* * *}$ & 3.3496 & 0.0022 & 1.1780 & $2.2369^{*}$ & $3.8260 * *$ & $8.9106^{* * * *}$ \\
\hline & FKLI+ & 0.3170 & 2.1593 & 4.7015 & 0.7003 & 0.7684 & -0.6511 & -1.4283 & -3.4640 \\
\hline & $R^{2}$ & 0.0706 & 0.2959 & 0.1037 & 0.0570 & 0.0259 & 0.0406 & 0.0487 & 0.2356 \\
\hline \multirow[t]{5}{*}{$\mathrm{CON}$} & $\mathrm{C}$ & $-4.3004 * * *$ & $-38.2066^{* * *}$ & $-18.6499^{* * * *}$ & $-9.6357 * * *$ & -1.3239 & $3.5105 * * *$ & $4.0843^{* * *}$ & $8.2690^{* * *}$ \\
\hline & CSI+ & 2.2239 & $14.8456^{* * *}$ & 1.4911 & 1.5487 & 0.5217 & 2.8841 & $6.8476^{* * *}$ & $5.2895^{* *}$ \\
\hline & $\mathrm{BCS}+$ & 2.3326 & 1.1365 & 2.3467 & 1.9285 & 0.6453 & -0.2169 & -0.1839 & $18.824^{* * *}$ \\
\hline & FKLI+ & $2.9609^{*}$ & $11.9807^{* * *}$ & $10.8452^{* * * *}$ & 3.3935 & 1.4777 & 0.4949 & 2.6018 & $4.7875^{*}$ \\
\hline & $R^{2}$ & 0.0558 & 0.2191 & 0.1343 & 0.0686 & 0.0159 & 0.0230 & 0.0480 & 0.269868 \\
\hline
\end{tabular}

Notes: The $R^{2}$ represents $R$-squared for OLS and Pseudo $R$-squared for QR. The asterisk (*), (**), and (***) denotes significant levels of $1 \%, 5 \%$, and $10 \%$ respectively. The $t$-Statistics are unreported due to space constraint.

Table 5c: Regression Tests (Negative Sentiments)

\begin{tabular}{|c|c|c|c|c|c|c|c|c|c|c|}
\hline \multirow{2}{*}{ Segmentation } & \multirow{2}{*}{ Indices } & \multirow{2}{*}{ Variables } & \multirow{2}{*}{$\frac{\text { Mean-Based }}{\text { OLS }}$} & \multicolumn{6}{|c|}{ Quantile-Based } & \multirow[b]{2}{*}{ q98 } \\
\hline & & & & $\mathrm{q} 02$ & $\mathrm{q} 10$ & $\mathrm{q} 20$ & q50 & q80 & q90 & \\
\hline \multirow{18}{*}{ Big Firms } & KLCI & $\overline{\mathrm{C}}$ & $\bar{~} 1.9319^{* * *}$ & $-8.9862 * * * *$ & $-4.6174 * * * *$ & $-2.2707^{* *}$ & 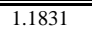 & $4.0147 * * *$ & $8.3545^{* * * *}$ & $18.734 * * *$ \\
\hline & & $\mathrm{R}_{t-1}$ & 0.1416 & 0.3343 & 0.2863 & $0.3071^{*}$ & 0.1605 & $0.1900 * *$ & 0.0426 & 0.312045 \\
\hline & & CSI- & -1.3158 & -3.5373 & -0.5335 & -0.5055 & -0.7022 & $-1.7843 * *$ & $-3.8170 * *$ & $-5.1465 * *$ \\
\hline & & BCS- & $-2.5150 * * *$ & $-8.2304 * *$ & -3.2174 & -1.8762 & -1.1859 & -0.9319 & -0.8031 & -9.1952 \\
\hline & & FKLI- & 0.1661 & -0.2252 & -2.7432 & -2.0397 & 0.5212 & $2.3087^{* * *}$ & 2.5051 & 13.0629 \\
\hline & & $R^{2}$ & 0.0775 & 0.2616 & 0.1348 & 0.0778 & 0.0205 & 0.0422 & 0.0433 & 0.2332 \\
\hline & ВMíno- & $\overline{\mathrm{C}}$ & $2.2624 * \cdots$ & $-8.7158^{*}$ *冰 & $-3.9203^{*}$ & $-\overline{2} .223 \overline{7}^{*}$ & $1.5477^{*}$ & $4.2173 * 3^{*}$ & $9.4533^{* * *}$ & $20.1639^{* *}$ \\
\hline & & $\mathrm{R}_{t-1}$ & 0.1035 & 0.2077 & 0.2517 & 0.2922 & 0.1047 & $0.1513^{*}$ & 0.0149 & 0.0324 \\
\hline & & CSI- & -1.4717 & -0.4189 & -0.5781 & -0.5790 & -0.8935 & $-1.9226 * *$ & $-4.2326^{* *}$ & $-5.4643 * *$ \\
\hline & & BCS- & $-2.5508 * * *$ & $-9.9292 *$ & $-2.9640 *$ & -1.8930 & -1.2151 & -1.0777 & -0.6082 & -8.8660 \\
\hline & & FKLI- & -0.3163 & -4.9210 & -3.9889 & -2.3420 & -0.0639 & $2.5463 * *$ & 1.2275 & 9.4640 \\
\hline & & $R^{2}$ & 0.0753 & 0.2800 & 0.1373 & 0.0731 & 0.0243 & 0.0379 & 0.0536 & 0.2189 \\
\hline & BMEMĀS & $\mathrm{C}$ & $2.2685^{*}$ * & 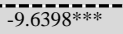 & $-3.3512^{* *}$ & $-2.7352^{* *}$ & $1.7758 *$ & $4.4318 * *$ & $8.9401 * *$ & $22.431^{*} *{ }^{*}$ \\
\hline & & $\mathrm{R}_{t-1}$ & 0.1028 & 0.2241 & 0.0955 & $0.3366^{* * *}$ & 0.0382 & $0.1504 *$ & 0.0600 & 0.0141 \\
\hline & & CSI- & $-1.6186^{*}$ & -2.0919 & -0.9479 & -0.3859 & -0.9588 & $-2.0332 * *$ & $-3.4171 *$ & $-5.9610^{* *}$ \\
\hline & & BCS- & $-2.5218^{* * *}$ & $-9.1655^{* *}$ & $-3.2328 *$ & -1.9355 & -0.8743 & -0.9393 & -0.2475 & $-10.590^{*}$ \\
\hline & & FKLI- & -0.3612 & -2.0270 & $-5.3727 * *$ & -1.9603 & -0.6478 & $2.0863 *$ & 1.2460 & 7.2540 \\
\hline & & $R^{2}$ & 0.0752 & 0.2756 & 0.1284 & 0.0726 & 0.0244 & 0.0372 & 0.0500 & 0.2264 \\
\hline \multirow{18}{*}{ Small Firms } & $\overline{\text { BM70 }}$ & $\mathrm{C}$ & $2.6889^{* * * *}$ & $-10.9277^{* * *}$ & $-5.9042 * * *$ & $-2.4375^{* * *}$ & 1.5768 & $6.4335 * * *$ & $9.4566^{* * *}$ & $23.814 * * *$ \\
\hline & & $\mathrm{R}_{t-1}$ & 0.0882 & $0.2530^{*}$ & 0.2422 & $0.2509 * *$ & 0.1324 & 0.0605 & -0.0175 & 0.0263 \\
\hline & & CSI- & $-1.9499^{*}$ & -4.6787 & 0.4061 & -1.5041 & -0.9591 & $-2.7775^{* *}$ & $-4.904 * * *$ & $-5.6687 * * *$ \\
\hline & & BCS- & $-2.6515^{* *}$ & $-9.0701 * *$ & -2.1528 & -1.7296 & -0.8004 & -1.0437 & 0.3875 & $-12.484 * *$ \\
\hline & & FKLI- & -0.9146 & -0.1481 & $-4.7735^{*}$ & $-3.7542 *$ & -0.9340 & 0.9190 & 0.2777 & $3.5124^{*}$ \\
\hline & & $R^{2}$ & 0.0766 & 0.2705 & 0.1303 & 0.0741 & 0.0144 & 0.0478 & 0.0693 & 0.2547 \\
\hline & $\overline{\mathrm{BMSC}}$ & $\mathrm{C}$ & $2.8294 * *$ & $-13.7889^{* * * *}$ & $-4.9096^{* * *}$ & $-1.9647^{*}$ & 1.6249 & $6.7423 * * *$ & $7.9338 * * *$ & $28.480^{* * * *}$ \\
\hline & & $\mathrm{R}_{t-1}$ & 0.0610 & $0.3112^{* * * *}$ & 0.0274 & 0.0830 & 0.0515 & 0.0235 & 0.0915 & 0.2028 \\
\hline & & CSI- & $-2.2274^{*}$ & $-10.5193^{* * * *}$ & $-3.5110^{*}$ & -2.0523 & -1.1119 & -1.9802 & -1.9808 & $-6.7550 * *$ \\
\hline & & BCS- & $-2.8095^{* *}$ & $-5.1059 *$ & -1.2228 & -2.2278 & -1.3021 & -1.4531 & 0.1808 & $-14.049^{* *}$ \\
\hline & & FKLI- & -1.1478 & 3.7757 & $-6.7354 * *$ & $-3.5458^{*}$ & -1.4389 & 0.3179 & 0.9617 & 4.5969 \\
\hline & & $R^{2}$ & 0.0662 & 0.2400 & 0.0939 & 0.0662 & 0.0176 & 0.0220 & 0.0202 & 0.2275 \\
\hline & $\overline{\mathrm{BMFL}}$ & $\mathrm{C}$ & $2.7537^{* * *}$ & $-14.7626^{\text {**** }}$ & $-6.8016^{\text {**** }}$ & $-2.6801^{* *}$ & 2.2003 & $6.7329 * * *$ & $11.539^{* * *}$ & $32.839 * * *$ \\
\hline & & $\mathrm{R}_{t-1}$ & 0.0774 & $0.3653^{* * * *}$ & 0.0916 & 0.0302 & -0.0009 & 0.0652 & 0.1001 & 0.2812 \\
\hline & & CSI- & $-2.8394 * *$ & $-15.0393^{* * *}$ & -3.7052 & -1.4785 & -1.6360 & $-2.5693^{*}$ & -3.8669 & -7.6112 \\
\hline & & BCS- & -2.0625 & -3.9489 & 0.7210 & -1.9256 & $-1.9181 *$ & -0.1985 & -2.5599 & $-14.291^{*}$ \\
\hline & & FKLI- & -1.1920 & -0.6986 & $-5.6974 *$ & -1.7218 & -1.5325 & -0.3418 & 2.2189 & 3.2077 \\
\hline & & $R^{2}$ & 0.0612 & 0.2202 & 0.0542 & 0.0317 & 0.0258 & 0.0295 & 0.0305 & 0.1720 \\
\hline \multirow{18}{*}{$\begin{array}{l}\text { Defensive } \\
\text { Industries }\end{array}$} & CSU & $\mathrm{C}$ & $1.8774 * * *$ & $-6.9632 * * *$ & $-3.6351 * * *$ & -0.4217 & $1.2440^{* * *}$ & $5.2833 * * *$ & $6.4268^{* * *}$ & $21.545^{* * * *}$ \\
\hline & & $\mathrm{R}_{t-1}$ & 0.0423 & -0.228755 & 0.0353 & -0.1076 & 0.0006 & -0.0266 & 0.0283 & 0.1225 \\
\hline & & CSI- & -0.9718 & $3.1889 * *$ & -1.1514 & -0.7858 & -0.2030 & $-1.7331 * *$ & $-2.391 * * *$ & $-3.2937 * * *$ \\
\hline & & BCS- & $-1.7256^{* *}$ & $-9.5602 *$ & -0.1153 & $-1.7812^{*}$ & -0.6153 & -1.0870 & -0.5553 & $-14.796^{* *}$ \\
\hline & & FKLI- & -0.5063 & $-12.3408^{* *}$ & $-3.9071 * *$ & $-2.1488^{* *}$ & -0.5086 & 0.3658 & 1.3289 & $3.1448 * *$ \\
\hline & & $R^{2}$ & 0.0454 & 0.1846 & 0.0615 & 0.0375 & 0.0081 & 0.0307 & 0.0561 & 0.2153 \\
\hline & $\overline{\text { PLN }}$ & $\mathrm{C}$ & $2.0193^{*}$ 水 & $-11.4736^{* * * *}$ & $-4.8741 * *$ & -1.9643 & $1.9941^{* * *}$ & 4.2990 *** & 7.8928 *** & $14.774 * * *$ \\
\hline & & $\mathrm{R}_{t-1}$ & 0.055042 & $0.4602 * *$ & 0.0092 & 0.1225 & 0.0610 & 0.1270 & 0.0022 & -0.2731 \\
\hline & & CSI- & -0.631721 & -0.0152 & 1.0415 & -0.0822 & $-1.4762 *$ & -0.8327 & -0.9626 & 1.5195 \\
\hline & & BCS- & -1.486712 & -6.8818 & -2.5338 & -1.6601 & -0.4794 & -0.2203 & 0.2117 & -1.9375 \\
\hline & & FKLI- & -1.372082 & -4.6745 & $-6.1283 *$ & $-3.4722 *$ & -0.7276 & 1.6153 & 2.4716 & -2.1998 \\
\hline & & $R^{2}$ & 0.039146 & 0.2392 & 0.1041 & 0.0467 & 0.0191 & 0.0126 & 0.0274 & 0.0537 \\
\hline & $\overline{S E R}$ & C & $1.9199^{* *}$ & $-11.8071^{\text {* }}$ & $-3.6889^{*}$ ** & -1.3835 & 0.9858 & $3.4409 * *$ & $8.4322 * *$ & $17.460^{* * *}$ \\
\hline & & $\mathrm{R}_{t-1}$ & 0.1046 & 0.4696 & 0.0893 & 0.1347 & 0.1664 & 0.1789 & 0.0472 & 0.223677 \\
\hline & & CSI- & -1.0909 & -2.1139 & -0.3828 & -0.2478 & -0.7073 & -1.1701 & -2.7066 & $-4.6474 * *$ \\
\hline & & BCS- & $-2.5075^{* * * *}$ & -7.8793 & -2.4259 & $-2.5491^{* *}$ & -0.8300 & -0.1275 & -2.0135 & $-7.2884^{*}$ \\
\hline & & FKLI- & -0.2210 & 0.3029 & $-5.5263 * *$ & -3.2318 & 0.3419 & 1.7121 & 3.6952 & 12.1396 \\
\hline & & $R^{2}$ & 0.0639 & 0.2449 & 0.1318 & 0.0765 & 0.0139 & 0.0152 & 0.0481 & 0.2082 \\
\hline \multirow{4}{*}{$\begin{array}{l}\text { Speculative } \\
\text { Industries }\end{array}$} & PRP & $\mathrm{C}$ & $2.4106^{* * *}$ & $-12.1604^{* * *}$ & $-6.0508 * * *$ & $-3.5144 * * *$ & 1.6629 & $6.6607 * * *$ & $10.775^{* * *}$ & $25.838^{* * *}$ \\
\hline & & $\mathrm{R}_{t-1}$ & 0.0984 & $0.3189^{* * *}$ & 0.0675 & $0.1753 * *$ & 0.0352 & 0.0758 & 0.0376 & -0.0526 \\
\hline & & CSI- & $-2.1165^{*}$ & $-10.258^{* * *}$ & -2.9318 & -1.6943 & -1.1436 & $-2.8696^{*}$ & -2.0937 & $-2.8828^{*}$ \\
\hline & & BCS- & $-2.7285^{* *}$ & $-4.7304 * *$ & -0.5065 & -0.9043 & -1.8929 & -0.4408 & -2.9790 & $-16.511^{* * *}$ \\
\hline
\end{tabular}




\begin{tabular}{|c|c|c|c|c|c|c|c|c|c|}
\hline & FKLI- & -0.8573 & 2.1285 & $-6.6663 * * *$ & $-3.9340^{*}$ & -1.1685 & 0.6045 & -0.3318 & 3.4193 \\
\hline & $R^{2}$ & 0.0744 & 0.2749 & 0.0929 & 0.0766 & 0.0228 & 0.0373 & 0.0450 & 0.2532 \\
\hline \multirow[t]{6}{*}{ FIN } & $\mathrm{C}$ & $3.0865^{* * *}$ & $-9.1224 * * *$ & $-3.4818 * *$ & $-3.0919^{* *}$ & $2.5475^{* *}$ & 5.8442 *** & $8.7174 * * *$ & $32.894 * * *$ \\
\hline & $\mathrm{R}_{t-1}$ & 0.0926 & $0.2346^{* * * *}$ & 0.1220 & $0.2661^{* *}$ & 0.1157 & $0.1030^{*}$ & $0.1468^{* *}$ & $-0.5317 * *$ \\
\hline & CSI- & $-2.6650 * *$ & $-11.2573^{* * * *}$ & -3.5742 & 0.0342 & -1.3479 & $-2.2359 * *$ & $-3.7264 * *$ & $-8.9106^{* * *}$ \\
\hline & BCS- & $-3.0547^{* *}$ & $-7.2420 * *$ & -4.5836 & -2.3080 & -1.0629 & -1.5457 & 0.0287 & $-16.0640 *$ \\
\hline & FKLI- & -0.2869 & -2.1593 & -4.9262 & -0.9178 & -0.9721 & 1.0881 & 1.3948 & 3.4640 \\
\hline & $R^{2}$ & 0.0815 & 0.2946 & 0.1025 & 0.0617 & 0.0257 & 0.0461 & 0.0484 & 0.2376 \\
\hline \multirow[t]{6}{*}{$\mathrm{CON}$} & $\mathrm{C}$ & $3.9765^{* * * *}$ & $-10.2438^{* * *}$ & $-4.0541 * * *$ & -1.6989 & $2.0388^{* *}$ & $7.1363^{* * *}$ & $13.751^{* * *}$ & $34.776^{* * *}$ \\
\hline & $\mathrm{R}_{t-1}$ & -0.0534 & $0.3054^{* * *}$ & 0.1149 & 0.1277 & -0.0419 & 0.0075 & -0.1331 & $-0.5684 * * *$ \\
\hline & CSI- & $-2.6520^{*}$ & $-14.8456^{* *}$ & -1.5865 & -1.9375 & -0.2380 & -2.4538 & $-6.829 * * *$ & $-9.1133^{* * * *}$ \\
\hline & BCS- & $-3.5356^{* *}$ & -1.1365 & -2.3719 & $-2.4585^{*}$ & $-2.0564^{*}$ & -1.3509 & -0.2346 & $-16.544 * * *$ \\
\hline & FKLI- & $-2.8645^{*}$ & $-11.9807 * *$ & $-10.1872 * * *$ & $-5.5521^{* *}$ & -1.7219 & -0.2107 & -2.8319 & -0.9446 \\
\hline & $R^{2}$ & 0.0729 & 0.21896 & 0.1340 & 0.0700 & 0.0207 & 0.0278 & 0.0484 & 0.3070 \\
\hline
\end{tabular}

Notes: The $R^{2}$ represents $R$-squared for OLS and Pseudo $R$-squared for QR. The asterisk (*), (**), and (***) denotes significant levels of $1 \%, 5 \%$, and $10 \%$ respectively. The $t$-Statistics are unreported due to space constraint.

Table 5d: Regression Tests (Positive Sentiment in Non-Crisis)

\begin{tabular}{|c|c|c|c|c|c|c|c|c|c|c|}
\hline \multirow{2}{*}{ Segmentation } & \multirow{2}{*}{ Indices } & \multirow{2}{*}{ Variables } & \multicolumn{3}{|l|}{ Mean-Based } & \multicolumn{2}{|c|}{ Quantile-Based } & \multirow[b]{2}{*}{ q80 } & \multirow[b]{2}{*}{ q90 } & \multirow[b]{2}{*}{ q98 } \\
\hline & & & OLS & q02 & $\mathrm{q} 10$ & $\mathrm{q} 20$ & $\mathrm{q} 50$ & & & \\
\hline \multirow{18}{*}{ Big Firms } & \multirow[t]{6}{*}{ KLCI } & $\mathrm{C}$ & $-1.3444 *$ & $-20.0097 * * *$ & $-11.1532 * * * *$ & -7.1960*** & $\begin{array}{l}-1.0226 \\
\end{array}$ & $3.6598 * * *$ & $6.5765^{* * * *}$ & 16.3515* \\
\hline & & $\mathrm{R}_{t-1}$ & 0.1137 & $0.4914 * * *$ & $0.2834 * * *$ & 0.2659 & 0.0272 & $0.1207 *$ & 0.0951 & -0.1617 \\
\hline & & $\mathrm{CSI}+* \mathrm{NC}$ & 1.7539 & -1.1115 & 0.3392 & 0.3640 & 1.1813 & $2.3202 * *$ & $4.1471^{* * * *}$ & 3.5645 \\
\hline & & $\mathrm{BCS}+* \mathrm{NC}$ & 1.0991 & 0.3729 & $3.2566^{* * *}$ & 1.5946 & 0.7892 & -0.7865 & -1.9224 & 8.3061 \\
\hline & & $\mathrm{FKLI}+* \mathrm{NC}$ & 0.6345 & $11.0711^{* * *}$ & $4.9635^{* * * *}$ & 3.1919 & 1.0293 & -1.1921 & -1.9913 & -5.6164 \\
\hline & & $R^{2}$ & 0.0694 & 0.2971 & 0.1785 & $0.1064 *$ & 0.0262 & 0.0410 & 0.0529 & 0.1269 \\
\hline & \multirow[t]{6}{*}{ BMín } & $\mathrm{C}$ & $-1.4552 *$ & -19.837 * & 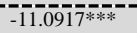 & -7.8198 * & $-1.311 \overline{7}$ & $4.1342 * *$ * & $6.7045^{*} * *$ & 18.1424 \\
\hline & & $\mathrm{R}_{t-1}$ & 0.0925 & $0.4832 * * *$ & $0.2788^{* * *}$ & 0.2117 & 0.0288 & 0.1029 & 0.0697 & -0.1295 \\
\hline & & $\mathrm{CSI}+* \mathrm{NC}$ & 1.8329 & -0.9157 & 0.2399 & 1.1587 & $1.4110^{*}$ & $2.4031 * *$ & $4.1295^{* * *}$ & 3.7360 \\
\hline & & $\mathrm{BCS}+* \mathrm{NC}$ & 1.0128 & 0.2754 & 3.2836 & 1.4088 & 1.0702 & -0.3432 & -1.0717 & 6.6065 \\
\hline & & FKLI+*NC & 0.9229 & $11.4007 * * *$ & $4.5014^{* *}$ & $4.1111 * * *$ & 1.0814 & $-1.8358^{*}$ & -1.9203 & -7.1011 \\
\hline & & $R^{2}$ & 0.0668 & 0.3146 & $0.1939 * * *$ & 0.1036 & 0.0334 & 0.0313 & 0.0560 & 0.1212 \\
\hline & \multirow[t]{6}{*}{$\overline{\mathrm{BMEMAS}}$} & $\bar{C}$ & -1.65969 * & $-18.1228^{* * * *}$ & $-12.0600^{* * * *}$ & -7.8664 皮水 & $-1 . \overline{1544}$ & $\overline{4} . \overline{8} \overline{2} 0^{* *} \bar{k}^{*}$ & 6.5217 * & $13.260^{* * *}$ \\
\hline & & $\mathrm{R}_{t-1}$ & 0.0870 & $0.4320 * * *$ & $0.2348 * * *$ & $0.2485 *$ & -0.0004 & 0.1046 & 0.0597 & $-0.4096 * * *$ \\
\hline & & $\mathrm{CSI}+\mathrm{NC}$ & $2.0129 *$ & $-2.6310^{* *}$ & 0.3212 & 0.6799 & 1.2020 & $2.6783 * *$ & $3.4195^{* * *}$ & 5.0486 \\
\hline & & $\mathrm{BCS}+* \mathrm{NC}$ & 0.9176 & -0.5129 & $2.4989^{*}$ & 1.6657 & 0.8465 & -0.5364 & -1.3076 & 7.9119 \\
\hline & & $\mathrm{FKLI}+* \mathrm{NC}$ & 1.1272 & $11.475^{* * * *}$ & $6.4981 * * *$ & $3.9105 * *$ & 1.4295 & -1.6540 & -0.9980 & -1.0016 \\
\hline & & $R^{2}$ & 0.0702 & 0.2996 & 0.1671 & 0.1085 & 0.0358 & 0.0310 & 0.0544 & 0.1475 \\
\hline \multirow{18}{*}{ Small Firms } & \multirow[t]{6}{*}{ BM70 } & $\bar{C}$ & $-2.0464^{* *}$ & $-20.7416^{* * *}$ & $-12.7225 * * *$ & $-8.8584 * * *$ & -1.4867 & $4.3398 * * *$ & $5.4646^{* * *}$ & $14.161 * * *$ \\
\hline & & $\mathrm{R}_{t-1}$ & 0.0812 & $0.3038^{* * * *}$ & $0.2216^{* * *}$ & 0.2043 & 0.0403 & 0.0958 & 0.0057 & $-0.4919 * * *$ \\
\hline & & $\mathrm{CSI}+* \mathrm{NC}$ & $2.4228^{*}$ & -2.9645 & 1.1174 & 0.9988 & 1.4154 & $3.7409 * * *$ & $4.6364 * * *$ & 4.9367 \\
\hline & & $\mathrm{BCS}+* \mathrm{NC}$ & 0.7406 & 0.9584 & $2.4697^{*}$ & $2.5908 *$ & 0.7193 & -1.1604 & -1.7813 & 4.9487 \\
\hline & & FKLI+*NC & 1.6327 & $11.6027 * * *$ & $6.3330 * * *$ & $3.8149^{*}$ & 1.8075 & -0.7163 & 0.2599 & -1.3273 \\
\hline & & $R^{2}$ & 0.0745 & 0.2702 & 0.1873 & 0.1102 & 0.0323 & 0.0423 & 0.0499 & 0.1590 \\
\hline & $\overline{\mathrm{BM}} \overline{\mathrm{M}} \overline{\mathrm{C}}$ & $\mathrm{C}$ & -2.5651 * & -26.048 *** & $-15.095 * * *$ & $-9.4123^{*} x_{*}$ & $-2.4490^{*}$ & 3.9177 * & $7.7578 * *$ & $17.326^{* * * *}$ \\
\hline & & $\mathrm{R}_{t-1}$ & 0.0543 & $0.2946 * * *$ & $0.1027^{*}$ & 0.0730 & -0.0008 & 0.0052 & 0.1124 & $-0.6310^{* * *}$ \\
\hline & & $\mathrm{CSI}+* \mathrm{NC}$ & $2.6061^{*}$ & -0.7520 & 2.7686 & 1.8474 & $2.4082 *$ & $3.0323 * *$ & 2.3416 & 5.4493 \\
\hline & & $\mathrm{BCS}+* \mathrm{NC}$ & 0.6953 & -0.2900 & 2.6066 & 2.4834 & 0.2647 & -1.8882 & -1.2869 & 3.6599 \\
\hline & & $\mathrm{FKLI}+* \mathrm{NC}$ & 2.2289 & $13.224 * * *$ & $6.4234^{* * *}$ & 3.3754 & $2.7156^{* * *}$ & 1.8403 & -0.9425 & 3.9516 \\
\hline & & $R^{2}$ & 0.0680 & 0.2290 & 0.1350 & 0.1003 & 0.0338 & 0.0296 & 0.0173 & 0.0903 \\
\hline & $\overline{\mathrm{BM}} \overline{\mathrm{M}} \overline{\mathrm{L}}$ & $\bar{C}$ & $-\overline{2} . \overline{9} 92^{*}$ ** & $-31.4579^{*} * *$ & 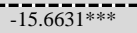 & $-\overline{7} . \overline{8084} \bar{*} * \bar{*}$ & $-\overline{2} . \overline{1012}$ * & $\overline{4} . \overline{18} \overline{1} 3^{*}-$ & $\overline{7} .66 \overline{4} 1^{*}$ * & $18 . \overline{4} 2^{* * * *}$ \\
\hline & & $\mathrm{R}_{t-1}$ & 0.0759 & $0.4029 * * *$ & 0.0444 & 0.0532 & -0.0455 & 0.0982 & 0.1090 & 0.1711 \\
\hline & & $\mathrm{CSI}+* \mathrm{NC}$ & $3.1994 * *$ & 7.3075 & 4.2064* & 2.3768 & $2.4162 *$ & $3.4726 * *$ & 2.0228 & 10.9108 \\
\hline & & $\mathrm{BCS}+* \mathrm{NC}$ & 0.1967 & 4.3471 & 2.1587 & 0.6297 & -0.5532 & -1.3369 & 0.662 & 4.6268 \\
\hline & & FKLI+*NC & 1.9561 & 5.0193 & $6.2160^{* * *}$ & $3.0472 *$ & $2.4432 *$ & 0.0216 & -0.6453 & -3.2457 \\
\hline & & $R^{2}$ & 0.0651 & 0.1863 & 0.0975 & 0.0595 & 0.0341 & 0.0334 & 0.0274 & 0.0829 \\
\hline & $\overline{\mathrm{CSU}}$ & $\mathrm{C}$ & $-1.0812^{*}$ & $-14.8937^{* * * *}$ & $-7.4087 * * *$ & $-5.0324 * * *$ & -0.0829 & $2.9889 * * *$ & $5.2526^{* * * *}$ & $6.2215^{* * *}$ \\
\hline & & $\mathrm{R}_{t-1}$ & 0.0245 & 0.2165 & $0.1399^{*}$ & 0.0451 & 0.0006 & 0.0367 & 0.0692 & -0.0489 \\
\hline & & $\mathrm{CSI}+* \mathrm{NC}$ & $1.7332 *$ & 2.0347 & 1.8784 & 1.1681 & 0.2268 & $2.4749 *$ & $2.8811^{* * *}$ & $4.7173^{* * * *}$ \\
\hline & & $\mathrm{BCS}+* \mathrm{NC}$ & 0.7933 & -2.5683 & 0.7545 & 0.7663 & 0.5915 & 0.3386 & -0.2990 & 12.7455 \\
\hline & & $\mathrm{FKLI}+* \mathrm{NC}$ & 0.7943 & 7.0223 & $2.3724^{*}$ & $2.5254 *$ & 0.7646 & -0.3855 & $-1.7293^{*}$ & $-2.5238^{* * *}$ \\
\hline & & $R^{2}$ & 0.0574 & $0.1527^{*}$ & 0.085117 & 0.0600 & 0.0149 & 0.0361 & 0.0625 & 0.0973 \\
\hline & $\overline{\text { PLN }}$ & $\mathrm{C}$ & -1.1233 & -20.658 *** & -11.8598 *** & -7.0958 *** & -0.5608 & $5.8068 * * *$ & $9.2566^{* * *}$ & $13.528^{* * *}$ \\
\hline & & $\mathrm{R}_{t-1}$ & 0.0669 & $0.5969 * * *$ & 0.1735 & $0.1747 *$ & 0.0081 & 0.1270 & -0.0095 & -0.1913 \\
\hline Defensive & & $\mathrm{CSI}+* \mathrm{NC}$ & 1.8401 & 1.0393 & 1.4662 & 1.7478 & $1.7661 *$ & 0.2815 & -0.2569 & -0.8590 \\
\hline Industries & & $\mathrm{BCS}+* \mathrm{NC}$ & 0.3833 & -1.2761 & 1.4099 & -0.0297 & -0.1455 & -0.3308 & 1.46967 & 1.1405 \\
\hline & & $\mathrm{FKLI}+* \mathrm{NC}$ & 1.1998 & $9.0574 * *$ & $5.4706^{* * *}$ & $3.9398 * *$ & 1.1458 & $-2.0096^{*}$ & $-3.4712^{* *}$ & -0.2591 \\
\hline & & $R^{2}$ & 0.0487 & 0.2462 & 0.1229 & 0.0692 & 0.0234 & 0.0136 & 0.0274 & 0.0427 \\
\hline & $\overline{\text { SER }}$ & $\bar{C}$ & $-1.3401 *$ & $-21.5668^{*}$ *** & $-11.186^{\text {* }}$ & $-7.6616^{*}$ & -1.0659 & $3.9252 * * *$ & 8.0439 *** & $20.853^{*}$ \\
\hline & & $\mathrm{R}_{t-1}$ & 0.0956 & $0.4321 * * *$ & $0.3552 * * *$ & $0.2078^{*}$ & 0.0059 & 0.0620 & 0.0920 & 0.0190 \\
\hline & & $\mathrm{CSI}+* \mathrm{NC}$ & 1.3346 & $-3.1461 * *$ & 0.4598 & 0.0336 & 0.8703 & $2.2934 * *$ & $3.5599 * *$ & 2.4092 \\
\hline & & $\mathrm{BCS}+* \mathrm{NC}$ & 1.1356 & -1.1296 & $2.6575^{* *}$ & $2.0064 *$ & 1.0505 & $-1.8106^{*}$ & -1.5158 & 6.6839 \\
\hline & & $\mathrm{FKLI}+* \mathrm{NC}$ & 0.8042 & $14.4782 * * *$ & $4.7038 * * *$ & $4.3026 * * *$ & 0.9056 & -0.8553 & -3.5515 & -10.7658 \\
\hline & & $R^{2}$ & 0.0531 & 0.2661 & 0.1884 & 0.1105 & 0.0188 & 0.0208 & 0.0456 & 0.1150 \\
\hline & $\overline{P R P}$ & $\mathrm{C}$ & $-2.8811^{* * *}$ & $-26.8627^{* * * *}$ & $-14.6035^{* * * *}$ & $-10.4793^{* * *}$ & $-2.8213^{* *}$ & $3.9546^{* * *}$ & $5.6873^{* * *}$ & $17.119^{* * *}$ \\
\hline $\begin{array}{l}\text { Speculative } \\
\text { Industries }\end{array}$ & & $\mathrm{R}_{t-1}$ & 0.0679 & $0.1917 * *$ & $0.1220^{* *}$ & 0.1250 & 0.0143 & 0.0752 & 0.1215 & $-0.6773^{* * *}$ \\
\hline & & $\mathrm{CSI}+* \mathrm{NC}$ & $2.3963^{*}$ & 0.0027 & 1.4942 & 1.2244 & 2.0568 & $2.8670 * *$ & 1.8174 & -4.2172 \\
\hline
\end{tabular}




\begin{tabular}{|c|c|c|c|c|c|c|c|c|c|}
\hline & $\mathrm{BCS}+* \mathrm{NC}$ & 1.0629 & 1.3786 & $2.4939^{*}$ & 1.7439 & 0.7846 & -1.7985 & 0.8434 & 6.2107 \\
\hline & $\mathrm{FKLI}+* \mathrm{NC}$ & 2.3209 & $13.4976^{* *}$ & $7.0360 * * *$ & $4.8066^{* *}$ & $2.8791 * *$ & 1.4958 & 0.4466 & 6.3362 \\
\hline & $R^{2}-$ & 0.0824 & 0.2365 & 0.1646 & 0.1144 & 0.0397 & 0.0470 & 0.0285 & 0.1191 \\
\hline \multirow[t]{6}{*}{ FIN } & $\mathrm{C}$ & $-2.0179^{* *}$ & $-27.7791^{*} * *$ & $-13.9491^{* * *}$ & $-7.9753^{* * *}$ & -0.8354 & $3.6721 * * *$ & $6.7248^{* * *}$ & $21.819^{* * *}$ \\
\hline & $\mathrm{R}_{t-1}$ & 0.0783 & $0.3809 * * *$ & $0.1075^{*}$ & 0.0631 & 0.1157 & 0.0764 & $0.1556^{* *}$ & $-0.5995 * * *$ \\
\hline & $\mathrm{CSI}+* \mathrm{NC}$ & $2.6488^{*}$ & 0.8005 & 2.1614 & 0.2661 & 1.5170 & $3.976 * * *$ & $4.5366^{* *}$ & 6.2956 \\
\hline & $\mathrm{BCS}+* \mathrm{NC}$ & 1.0308 & 0.1376 & $3.3845^{*}$ & 1.2740 & 0.8938 & -1.2940 & -1.1332 & 7.9234 \\
\hline & $\mathrm{FKLI}+* \mathrm{NC}$ & 1.4120 & $18.0339^{* * *}$ & $5.6763^{* *}$ & $4.7270^{* *}$ & 1.1412 & -0.4974 & -0.9224 & -3.8792 \\
\hline & $R^{2}-$ & 0.0697 & 0.2999 & 0.1600 & 0.0795 & 0.0345 & 0.0442 & 0.0468 & 0.1429 \\
\hline \multirow[t]{6}{*}{$\mathrm{CON}$} & $\mathrm{C}$ & $-3.3119^{* * *}$ & $-25.0894 * * *$ & $-17.4885^{* * *}$ & $-9.8768 * * *$ & $-2.0152^{*}$ & $3.9805 * * *$ & $7.1577^{* * *}$ & $16.740^{* * *}$ \\
\hline & $\mathrm{R}_{t-1}$ & -0.0335 & $0.3054 * * *$ & $0.1550^{* *}$ & 0.1280 & -0.0227 & 0.0319 & -0.0326 & $-0.4244 * * *$ \\
\hline & $\mathrm{CSI}+* \mathrm{NC}$ & 2.3389 & -1.8093 & 1.0131 & 1.5286 & 0.9465 & $3.7466 * *$ & $5.8487 * * *$ & 3.7084 \\
\hline & $\mathrm{BCS}+* \mathrm{NC}$ & 1.0568 & -3.6166 & $4.2749 * *$ & 2.2293 & 1.0826 & -2.2040 & -2.3178 & 8.2058 \\
\hline & $\mathrm{FKLI}+* \mathrm{NC}$ & $3.3805^{* * *}$ & $15.5185^{* * * *}$ & $9.1474 * * *$ & $4.7928 * *$ & $2.2103^{*}$ & 1.4688 & -0.0781 & -1.1917 \\
\hline & $R^{2}$ & 0.0594 & 0.2041 & 0.1852 & 0.1048 & 0.0292 & 0.0265 & 0.0400 & 0.1443 \\
\hline
\end{tabular}

Notes: The $R^{2}$ represents $R$-squared for OLS and Pseudo $R$-squared for QR. The asterisk (*), (**), and (***) denotes significant levels of $1 \%, 5 \%$, and $10 \%$ respectively. The $t$-Statistics are unreported due to space constraint.

Table 5e: Regression Tests (Positive Sentiment in Crisis)

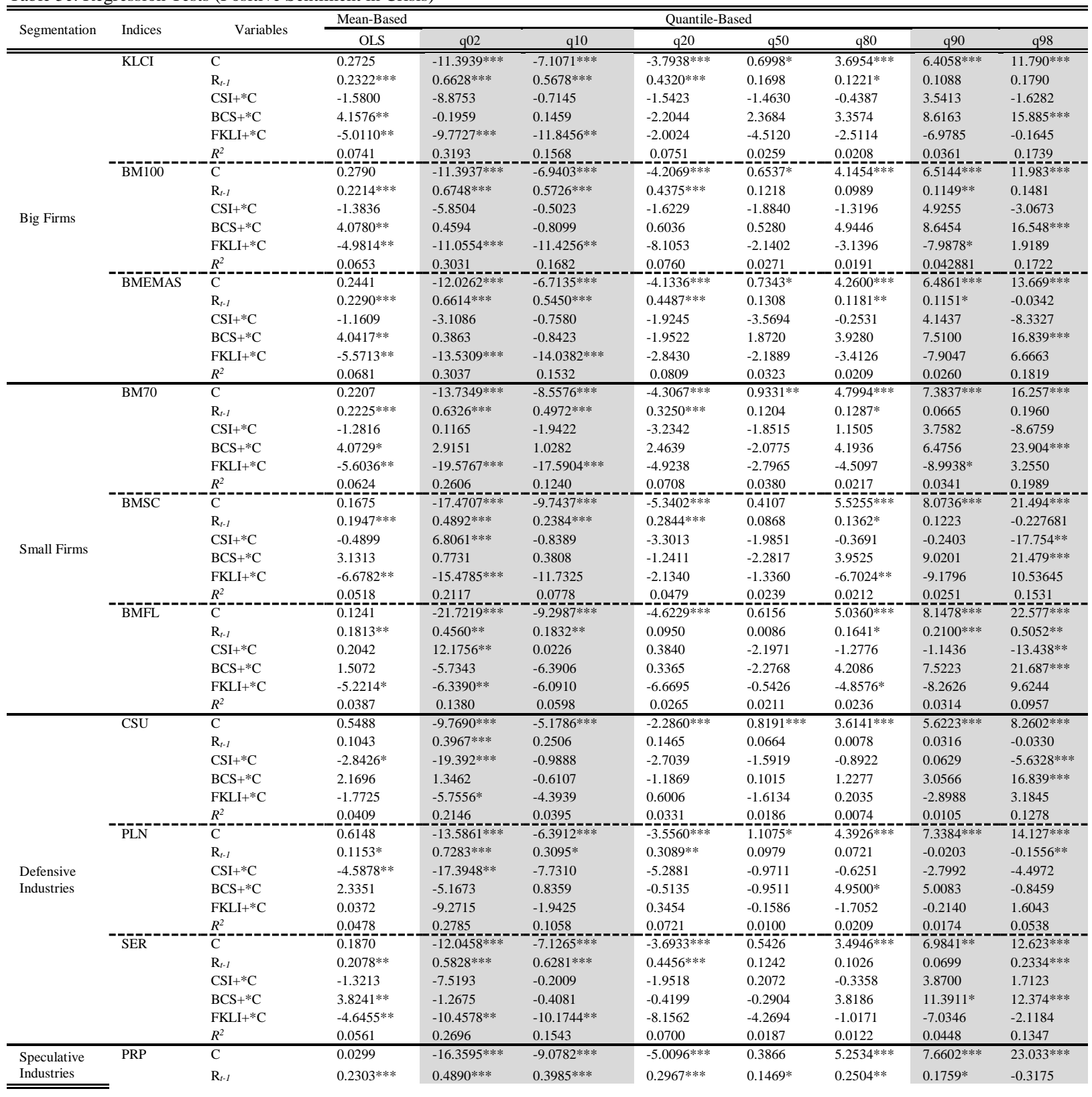




\begin{tabular}{|c|c|c|c|c|c|c|c|c|c|}
\hline & $\mathrm{CSI}+* \mathrm{C}$ & -0.1764 & $6.7883 * * *$ & 0.1636 & -1.4149 & -1.9926 & -0.6476 & 1.9151 & -12.0358 \\
\hline & $\mathrm{BCS}+{ }^{*} \mathrm{C}$ & 3.2076 & -1.6371 & -0.2675 & -2.8931 & -1.8388 & 4.9866 & 11.245 & 14.0300 \\
\hline & FKLI+*C & $-7.5974 * * *$ & $-11.1722^{* * * *}$ & $-16.2307^{* * *}$ & -7.0951 & -3.8231 & $-6.6904 * *$ & -11.2081 & -3.9300 \\
\hline & $R^{2}-$ & 0.0720 & 0.2223 & 0.0943 & 0.0775 & 0.0356 & 0.0372 & 0.0472 & 0.1932 \\
\hline \multirow[t]{6}{*}{ FIN } & $\mathrm{C}$ & 0.2615 & $-13.6327 * * *$ & $-7.9649 * * *$ & $-3.9658^{* * *}$ & $1.1292^{* *}$ & $4.0198^{* * * *}$ & $6.8527^{* * *}$ & $15.497 * * *$ \\
\hline & $\mathrm{R}_{t-1}$ & $0.2274 * * *$ & $0.5373 * * *$ & $0.3915 * * *$ & $0.2987 * * *$ & $0.1575 * *$ & $0.1644 * * *$ & 0.0859 & 0.1889 \\
\hline & $\mathrm{CSI}+{ }^{*} \mathrm{C}$ & 0.5040 & 0.9159 & 1.6250 & 0.3040 & -0.2126 & 1.4994 & 4.8100 & -9.6487 \\
\hline & $\mathrm{BCS}+{ }^{*} \mathrm{C}$ & $5.0910 * *$ & -4.2541 & -3.6332 & 0.3082 & 2.3466 & 3.0458 & 7.0324 & $38.387 * * *$ \\
\hline & FKLI+* C & $-8.4022 * * *$ & -17.8054 & $-15.1069 * * *$ & $-12.9674 * * *$ & $-6.3590^{*}$ & -3.4802 & -8.6245 & 6.3126 \\
\hline & $R^{2}-$ & 0.0727 & 0.2170 & 0.1340 & 0.0854 & 0.0299 & 0.0348 & 0.0226 & 0.2260 \\
\hline \multirow[t]{6}{*}{$\mathrm{CON}$} & $\mathrm{C}$ & -0.1141 & $-20.1097 * * *$ & $-9.2538 * * *$ & $-5.0880 * * *$ & 0.5062 & $4.6978 * * *$ & $8.3058^{* * *}$ & $17.297 * * *$ \\
\hline & $\mathrm{R}_{t-1}$ & $0.1197 *$ & $0.5864 * * *$ & $0.3557^{* * * *}$ & $0.2672 * * *$ & 0.0921 & 0.0707 & 0.0089 & -0.0594 \\
\hline & $\mathrm{CSI}+* \mathrm{C}$ & 0.1728 & 5.9815 & -0.8966 & -1.3512 & -1.3247 & -1.2413 & 9.1700 & -3.4298 \\
\hline & $\mathrm{BCS}+{ }^{*} \mathrm{C}$ & 3.6937 & 0.3166 & -5.0262 & -3.8282 & -0.8617 & 1.9754 & 11.4700 & 31.8113 \\
\hline & $\mathrm{FKLI}+* \mathrm{C}$ & $-6.3020^{*}$ & -19.5035 & $-10.934 * * *$ & -0.6611 & -4.4664 & 0.7814 & -12.385 & $-0.1991^{*}$ \\
\hline & $R^{2}$ & 0.0257 & 0.1470 & 0.107717 & 0.0539 & 0.0248 & 0.0101 & 0.0093 & 0.2863 \\
\hline
\end{tabular}

Notes: The $R^{2}$ represents $R$-square

Table 5f: Regression Tests (Negative Sentiment in Non-Crisis)

\begin{tabular}{|c|c|c|c|c|c|c|c|c|c|c|}
\hline \multirow{2}{*}{ Segmentation } & \multirow{2}{*}{ Indices } & \multirow{2}{*}{ Variables } & \multirow{2}{*}{$\begin{array}{c}\text { Mean-Based } \\
\text { OLS }\end{array}$} & \multicolumn{6}{|c|}{ Quantile-Based } & \multirow[b]{2}{*}{ q98 } \\
\hline & & & & $\mathrm{q} 02$ & $\mathrm{q} 10$ & $\mathrm{q} 20$ & $\mathrm{q} 50$ & $\mathrm{q} 80$ & $\mathrm{q} 90$ & \\
\hline \multirow{18}{*}{ Big Firms } & KLCI & $\mathrm{C}$ & -0.4452 & $-19.4020 * * *$ & $-9.5166 * *$ & $-6.1843 * * *$ & 0.2936 & $4.0502 * * *$ & 6.8099 *** & $21.448 * * *$ \\
\hline & & $\mathrm{R}_{t-1}$ & $0.2249 * * *$ & $0.5899 * * *$ & $0.4731^{* * *}$ & $0.4434 * * *$ & $0.2542 * *$ & $0.1303 * *$ & 0.095094 & 0.017356 \\
\hline & & CSI-*NC & -0.0500 & $7.2359 * * *$ & $3.4171^{*}$ & 1.9372 & -0.0860 & $-2.056^{* * *}$ & $-3.892 * * *$ & $-6.217 * *$ \\
\hline & & BCS-*NC & -0.0071 & $5.5807 * *$ & 0.5185 & 0.3814 & -0.4268 & -0.1616 & 1.9224 & -8.9473 \\
\hline & & FKLI-*NC & $2.1798^{*}$ & 1.2280 & $3.1327 *$ & 2.6279 & $1.6921 *$ & 1.5954 & 1.5004 & 1.0713 \\
\hline & & $R^{2}$ & 0.0506 & 0.2872 & 0.1699 & 0.0805 & 0.0161 & 0.0381 & 0.0514 & 0.1868 \\
\hline & BM 100 & $\mathrm{C}$ & -0.3839 & $-18.8085^{*}$ *** & $-9.0163^{*} * *$ & $-5.9094 * * *$ & 0.3207 & 4.2817 *** & $7.8419^{*} * *$ & $22.045 * * *$ \\
\hline & & $\mathrm{R}_{t-1}$ & $0.2061^{* * *}$ & $0.5592^{* * *}$ & $0.4371^{* * *}$ & $0.4264 * *$ & 0.2114 & $0.1277^{*}$ & 0.0697 & 0.0185 \\
\hline & & CSI-*NC & -0.0376 & $7.1676^{* * *}$ & $3.8175^{* *}$ & 0.8994 & -0.2076 & $-2.0103 * *$ & $-3.4595^{* *}$ & $-7.4169^{* * *}$ \\
\hline & & BCS-*NC & 0.0556 & $4.7757 * *$ & 0.1558 & 0.6554 & -0.4627 & -0.5248 & 0.8728 & $-8.7573^{*}$ \\
\hline & & FKLI-*NC & $1.9455^{*}$ & 2.1194 & 2.2344 & 2.4899 & 1.2649 & 1.7421 & 1.3803 & 1.8587 \\
\hline & & $R^{2}$ & 0.0422 & 0.2820 & 0.1668 & 0.0758 & 0.0141 & 0.0332 & 0.0535 & 0.1799 \\
\hline & BMEMAS & $\mathrm{C}$ & -0.3986 & $-18.1228^{* * * *}$ & $-10.0958^{\text {**** }}$ & $-6.1401 * * *$ & 0.3828 & $4.6205^{* * *}$ & 7.1731 *** & $23.709 * * *$ \\
\hline & & $\mathrm{R}_{t-1}$ & $0.2054 * * *$ & $0.4320 * * *$ & $0.5423 * * *$ & $0.4327 * * *$ & 0.1694 & 0.1024 & 0.0765 & -0.1691 \\
\hline & & CSI-*NC & -0.1278 & $5.7233 * * *$ & $3.9608 * *$ & 2.1125 & -0.0255 & $-2.408 * * *$ & $-3.416 * * *$ & $-8.9574 * * *$ \\
\hline & & $\mathrm{BCS}-* \mathrm{NC}$ & 0.1075 & $6.5144 * *$ & 0.1860 & -0.0106 & -0.1546 & -0.3310 & 1.4756 & $-8.7326^{*}$ \\
\hline & & FKLI-*NC & 1.8176 & -0.7738 & 3.1923 & 1.9948 & 0.7576 & 1.5892 & 1.1162 & 0.9778 \\
\hline & & $R^{2}$ & 0.0406 & 0.2700 & $0.1587^{*}$ & 0.0727 & 0.0129 & 0.0333 & 0.0485 & 0.2012 \\
\hline \multirow{18}{*}{ Small Firms } & BM70 & $\mathrm{C}$ & -0.3070 & $-19.6247 * * *$ & $-10.8357 * * *$ & $-7.0869 * * *$ & 0.0242 & 5.5616 *** & $8.2569^{* * * *}$ & $24.566^{* * * *}$ \\
\hline & & $\mathrm{R}_{t-1}$ & $0.1973 * * *$ & $0.3561 * * *$ & $0.4045^{* * *}$ & $0.4135 * * *$ & 0.1646 & 0.085591 & 0.0637 & $-0.4017 * *$ \\
\hline & & CSI-*NC & -0.2873 & $5.6774 * *$ & $4.3126^{* *}$ & 0.3288 & 0.1130 & $-2.2885^{* *}$ & $-4.236 * * *$ & $-9.9297 * * *$ \\
\hline & & BCS-*NC & 0.2055 & 5.5561 & 0.4200 & 2.1567 & 0.4169 & -0.4492 & 0.5282 & $-7.6624 * * *$ \\
\hline & & FKLI-*NC & 1.4191 & -0.6709 & 1.2317 & 2.1919 & 0.8566 & 1.2817 & 0.5509 & -1.0764 \\
\hline & & $R^{2}$ & 0.0362 & 0.2471 & 0.1251 & 0.0575 & 0.0133 & 0.0375 & 0.0551 & 0.2380 \\
\hline & $\mathrm{BMSC}$ & $\mathrm{C}$ & -0.1349 & 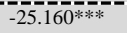 & $-11.2999^{* * * *}$ & $-6.3475^{* * *}$ & -0.3424 & $6.1766^{* * *}$ & $7.7578^{* * *}$ & $33.196^{* * *}$ \\
\hline & & $\mathrm{R}_{t-1}$ & $0.1611^{* *}$ & $0.3304 * * *$ & $0.2083^{* *}$ & $0.2521 * * *$ & 0.0560 & 0.0882 & 0.1124 & $-0.8205^{* * * *}$ \\
\hline & & CSI-*NC & -0.3678 & 4.2255 & 2.1177 & -0.4125 & 0.7227 & -1.5277 & 2.3416 & $-12.020^{* * *}$ \\
\hline & & $\mathrm{BCS}-* \mathrm{NC}$ & -0.1966 & 9.4412 & 1.1262 & 1.0673 & 0.0843 & -0.1960 & -1.2869 & -4.0100 \\
\hline & & FKLI-*NC & 0.8396 & $0.6920 * *$ & 0.6323 & 0.3246 & 0.5099 & -0.0691 & -0.9425 & $-13.751 * * *$ \\
\hline & & $R^{2}$ & 0.0241 & 0.1806 & 0.0560 & 0.0248 & 0.0042 & 0.0140 & 0.0173 & 0.2087 \\
\hline & $\mathrm{BMFL}$ & $\mathrm{C}$ & -0.1495 & -27.5564 *** & $-12.0340^{\text {**** }}$ & -6.3954 *** & -0.4089 & $5.4524 * * *$ & $10.211^{* * *}$ & $33.181 * * *$ \\
\hline & & $\mathrm{R}_{t-l}$ & $0.1642 *$ & $0.3144^{* *}$ & $0.1861^{* *}$ & $0.1388^{*}$ & 0.0689 & 0.1539 & $0.1767 * *$ & 0.0141 \\
\hline & & CSI-*NC & -0.8961 & $6.7581^{*}$ & 2.6198 & -0.3618 & 0.5896 & -1.7027 & -2.4591 & $-17.936 * *$ \\
\hline & & BCS-*NC & 0.2671 & $9.4138 * *$ & 2.7094 & 1.6971 & 0.4106 & 0.5374 & -1.8109 & $-5.4149^{*}$ \\
\hline & & FKLI-*NC & 0.8829 & 1.2209 & 0.2439 & 1.1262 & 0.9714 & 0.7394 & 0.1196 & -2.1500 \\
\hline & & $R^{2}$ & 0.0267 & 0.1651 & 0.0353 & 0.0134 & 0.0065 & 0.0232 & 0.0332 & 0.2010 \\
\hline \multirow{18}{*}{$\begin{array}{l}\text { Defensive } \\
\text { Industries }\end{array}$} & CSU & $\mathrm{C}$ & -0.0292 & -15.7977 & $-7.3185 * * *$ & $-3.8529 * * *$ & 0.4640 & $4.6036^{* * * *}$ & $5.7840^{* * * *}$ & $21.963^{* *}$ \\
\hline & & $\mathrm{R}_{t-1}$ & $0.1295^{*}$ & 0.4747 & $0.1363^{*}$ & 0.1989 & 0.1010 & 0.0436 & 0.0551 & -0.0559 \\
\hline & & CSI-*NC & -0.2717 & 4.6472 & 1.0329 & 1.5708 & 0.2329 & $-1.6429 * *$ & $-2.470 * * *$ & $-4.9811 * * *$ \\
\hline & & BCS-*NC & 0.1528 & 1.8685 & 1.9147 & 0.4779 & -0.1029 & -0.4213 & 0.1593 & -13.4789 \\
\hline & & FKLI-*NC & 1.4004 & 1.2189 & 1.1051 & 1.1247 & 0.5169 & 1.1932 & 1.5865 & 1.6802 \\
\hline & & $R^{2}$ & 0.0211 & 0.1247 & 0.0455 & 0.0254 & 0.0050 & 0.0274 & 0.0579 & 0.1142 \\
\hline & PLN & $\mathrm{C}$ & -0.2929 & $-20.3686^{* * * *}$ & $-11.4232^{*} * *$ & -5.5607 * & $1.1312^{*}$ & $4.7486^{* * * *}$ & $9.3721 * * *$ & $13.696^{* * * *}$ \\
\hline & & $\mathrm{R}_{t-1}$ & $0.1524 * *$ & $0.6135 * * *$ & $0.4991 * * *$ & $0.2634 * *$ & 0.1123 & 0.0986 & -0.0257 & -0.1813 \\
\hline & & CSI-*NC & -0.0244 & $7.3008 * * *$ & $4.5652 * * *$ & 1.7914 & -0.8193 & -1.1671 & $-3.0253^{*}$ & 0.6339 \\
\hline & & $\mathrm{BCS}-* \mathrm{NC}$ & 0.8040 & 2.3109 & 1.3531 & 0.5561 & -0.0520 & 0.2433 & 0.3457 & -1.3385 \\
\hline & & FKLI-*NC & 1.3407 & $6.7509 * * *$ & 1.8411 & 1.3434 & 0.4483 & 1.0553 & 0.9023 & -1.1869 \\
\hline & & $R^{2}$ & 0.0274 & 0.2649 & 0.1178 & 0.0368 & 0.0101 & 0.0089 & 0.0280 & 0.0466 \\
\hline & SER & $\mathrm{C}$ & $-0 . \overline{5} 130$ & 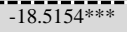 & $-11.1117^{* * * *}$ & $-6.3035^{* * *}$ & 0.0419 & $3.6601 * * *$ & 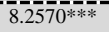 & $22.113^{* * *}$ \\
\hline & & $\mathrm{R}_{t-1}$ & $0.1895^{* * *}$ & $0.6618^{* * *}$ & $0.41550 * * *$ & $0.3544 * *$ & 0.2481 & 0.1206 & 0.0809 & 0.0651 \\
\hline & & CSI-*NC & 0.3170 & $7.2064 * * *$ & $4.3930 * *$ & 2.6281 & -0.3195 & -1.3391 & $-3.6709 * *$ & $-6.2333 * * *$ \\
\hline & & $\mathrm{BCS}-* \mathrm{NC}$ & -0.1011 & 2.4081 & 1.0760 & 0.2886 & -0.0392 & 0.0450 & -0.5509 & $-10.140^{* *}$ \\
\hline & & FKLI-*NC & 1.8656 & 2.1448 & $3.1789^{*}$ & 2.2955 & 1.3791 & 1.1789 & 3.8684 & 2.8930 \\
\hline & & $R^{2}$ & 0.0379 & 0.2859 & 0.1694 & 0.0691 & 0.0118 & 0.0146 & 0.0450 & 0.1673 \\
\hline Speculative & PRP & $\mathrm{C}$ & -0.5215 & $-23.0678^{* * * *}$ & $-12.0200^{* * * *}$ & $-7.9396 * * * *$ & -0.4681 & 5.6148 **** & $8.9468^{* * * *}$ & $29.225 * * *$ \\
\hline
\end{tabular}




\begin{tabular}{|c|c|c|c|c|c|c|c|c|c|c|}
\hline \multirow[t]{17}{*}{ Industries } & & $\mathrm{R}_{t-1}$ & $0.1972 * * *$ & $0.3353 * * *$ & $0.2178^{* *}$ & $0.2955 * * *$ & 0.1753 & 0.1543 & 0.1142 & $-0.8113^{* * *}$ \\
\hline & & CSI-*NC & -0.1055 & $6.2273 * * *$ & 2.4299 & 1.0458 & -0.0985 & -1.7427 & -1.8005 & $-5.6634 * * *$ \\
\hline & & BCS-*NC & -0.0443 & $8.2602 * * *$ & 2.1222 & 1.7916 & 0.3327 & 0.8120 & -1.3322 & $-9.1122 * * *$ \\
\hline & & FKLI-*NC & 1.0820 & 0.0441 & 0.0026 & 1.3173 & 1.0250 & 0.5568 & -0.2175 & $-11.403^{* * *}$ \\
\hline & & $R^{2}$ & 0.0354 & 0.1960 & 0.0885 & 0.0597 & 0.0100 & 0.0311 & 0.0335 & 0.2475 \\
\hline & FIN & $\mathrm{C}$ & -0.1883 & $-23.4908^{* * * *}$ & $-11.6934^{* * *}$ & $-5.6648 * * *$ & 1.1241 & $5.0400^{* * *}$ & $7.6587 * * *$ & $30.156^{* * * *}$ \\
\hline & & $\mathrm{R}_{t-1}$ & $0.1865^{* * * *}$ & $0.2961^{* * * *}$ & $0.4820^{* * * *}$ & $0.3323 * * *$ & $0.1576^{*}$ & $0.1174 * *$ & $0.1691^{* * *}$ & -0.2494 \\
\hline & & CSI-*NC & -0.4943 & $7.7402 * *$ & $4.0771^{* *}$ & 0.7157 & -0.1747 & $-2.958 * * *$ & $-3.1148^{* *}$ & $-14.004^{* * *}$ \\
\hline & & BCS-*NC & 0.1686 & $6.3452 *$ & 1.9237 & 0.9950 & -0.2042 & -0.2089 & 1.0428 & $-8.8793^{* *}$ \\
\hline & & FKLI-*NC & 1.7300 & $3.7330^{*}$ & $3.2333^{*}$ & 1.8162 & 0.3301 & 1.7102 & 1.9450 & -2.4287 \\
\hline & & $R^{2}$ & 0.0335 & 0.2118 & 0.1211 & 0.0621 & 0.0144 & 0.0379 & 0.0390 & 0.2205 \\
\hline & $\mathrm{CON}$ & $\mathrm{C}$ & -0.3831 & $-25.0894 * * *$ & $-14.5870^{* * *}$ & $-6.7853 * * *$ & 0.3665 & $5.2979 * * *$ & $9.2313^{* * *}$ & $33.966 * * *$ \\
\hline & & $\mathrm{R}_{t-1}$ & 0.0800 & $0.3054^{* * * *}$ & 0.3188 & $0.2849 * * *$ & 0.1165 & 0.0598 & -0.0371 & $-0.5627 * * *$ \\
\hline & & CSI-*NC & 0.3298 & $8.5169^{* *}$ & $6.7407^{*}$ & 0.5180 & -0.2023 & -1.6457 & $-3.4653^{*}$ & $-12.402^{* * *}$ \\
\hline & & BCS-*NC & -0.0940 & 7.0016 & 1.9797 & 1.0969 & -0.2135 & 0.1077 & 0.9086 & $-12.478^{* * *}$ \\
\hline & & FKLI-*NC & 0.2724 & -3.2044 & -1.8849 & 1.7718 & 0.1971 & 0.3924 & -0.3131 & $-6.4805^{* * *}$ \\
\hline & & $R^{2}$ & 0.0063 & 0.1837 & 0.0916 & 0.0356 & 0.0074 & 0.0151 & 0.0207 & 0.2997 \\
\hline
\end{tabular}

Notes: The $R^{2}$ represents $R$-squared for OLS and Pseudo $R$-squared for QR. The asterisk (*), (**), and (***) denotes significant levels of $1 \%, 5 \%$, and $10 \%$ respectively. The $t$-Statistics are unreported due to space constraint.

Table 5g: Regression Tests (Negative Sentiment in Crisis)

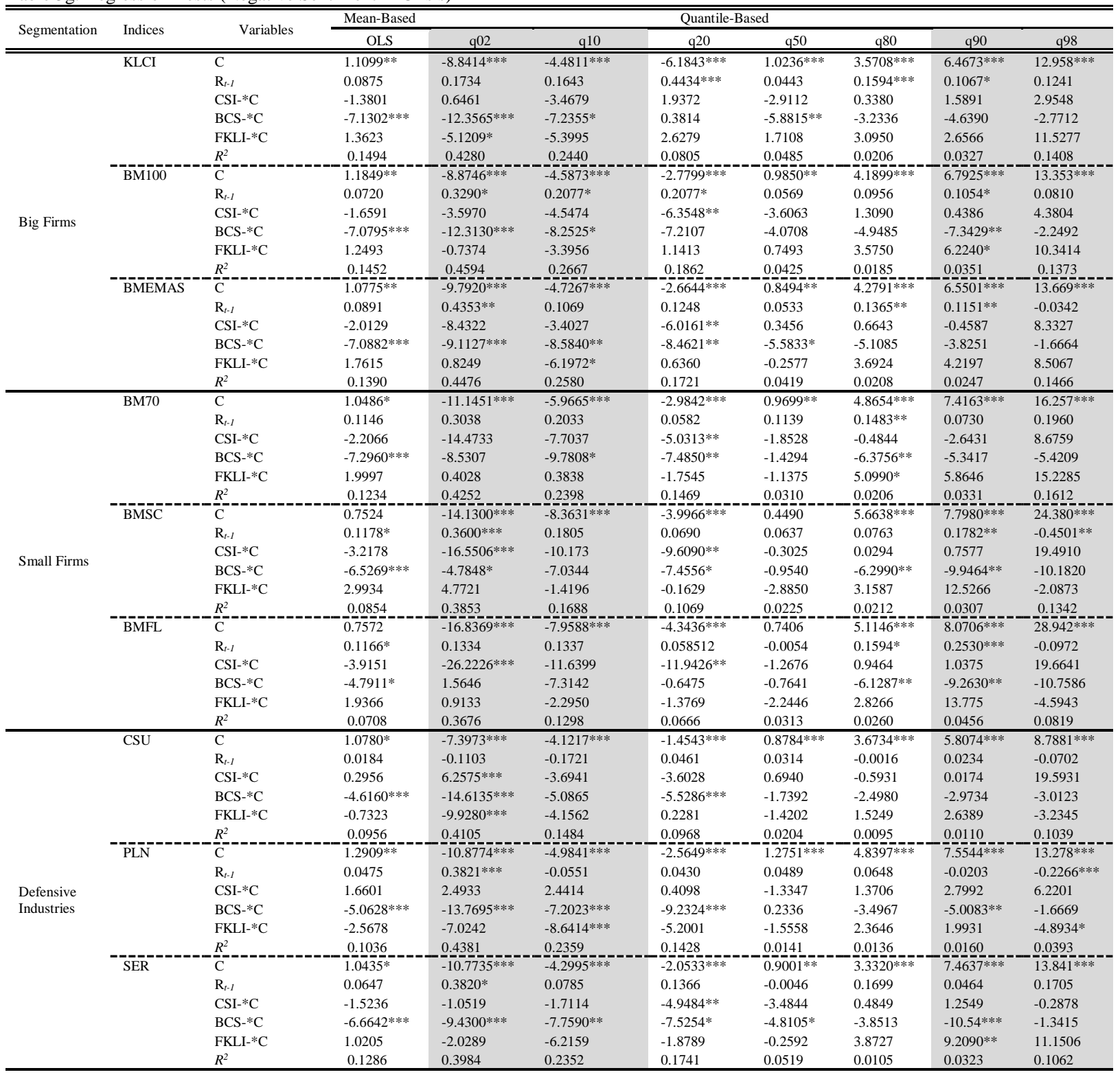




\begin{tabular}{|c|c|c|c|c|c|c|c|c|c|c|}
\hline \multirow{18}{*}{$\begin{array}{l}\text { Speculative } \\
\text { Industries }\end{array}$} & \multirow[t]{6}{*}{ PRP } & $\mathrm{C}$ & 0.605553 & $-13.3612^{* * * *}$ & $-8.2402 * * *$ & $-4.5571 * * *$ & 0.6040 & $5.2446 * * *$ & $8.0791 * * *$ & $23.035^{* * * *}$ \\
\hline & & $\mathrm{R}_{t-1}$ & $0.1447^{* *}$ & $0.1915^{*}$ & $0.2637 * * *$ & 0.1468 & 0.1287 & $0.2515^{* *}$ & $0.1766^{*}$ & -0.3175 \\
\hline & & CSI-*C & $-3.8120^{*}$ & $-13.9745^{* * * *}$ & $-13.6635^{* * *}$ & $-8.1045^{*}$ & -2.0206 & -1.4667 & -1.9137 & 12.0358 \\
\hline & & BCS $-* C$ & $-6.8656^{* * *}$ & -2.4691 & $-5.1209 * *$ & -6.0275 & -1.9499 & $-5.7746^{*}$ & -9.7157 & $-15.966^{* *}$ \\
\hline & & FKLI-*C & 3.5105 & 1.9685 & 2.0637 & -0.0270 & -0.4840 & 4.3530 & $10.780 * * *$ & 1.9942 \\
\hline & & $R^{2}$ & 0.1095 & 0.3977 & 0.2006 & 0.1301 & 0.0248 & 0.0354 & 0.0449 & 0.1969 \\
\hline & \multirow[t]{5}{*}{ FIN } & $\mathrm{C}$ & $1.2685^{* *}$ & $-10.7816^{* * * *}$ & $-5.4616 * * *$ & $-3.1201 * * *$ & $1.2383 * * *$ & $4.3649 * * *$ & $7.0520 * * *$ & $16.631 * * *$ \\
\hline & & $\mathrm{R}_{t-1}$ & 0.108487 & $0.3228 * * *$ & $0.1790 * * *$ & $0.1667 * *$ & $0.1507 *$ & $0.1287 * * *$ & 0.0866 & 0.3002 \\
\hline & & CSI $-* \mathrm{C}$ & $-4.3858 * *$ & $-14.0572 * * *$ & $-12.1008 * * *$ & $-13.8250 * * *$ & -0.8577 & -1.2220 & -1.7965 & 20.9070 \\
\hline & & BCS $-{ }^{*} \mathrm{C}$ & $-8.7396 * * * *$ & $-5.9469 * *$ & $-6.4434 * *$ & $-7.1144 * *$ & -6.5830 & -1.8710 & -4.0230 & -4.8055 \\
\hline & & FKLI-*C & 4.5107 & 0.2353 & -3.3737 & 3.2037 & 2.4957 & 2.5447 & 5.4006 & $18.288^{*}$ \\
\hline & \multirow{7}{*}{$\mathrm{CON}$} & $R^{2}$ & 0.1405 & 0.4785 & 0.2883 & 0.1799 & 0.0395 & 0.0337 & 0.0193 & 0.1762 \\
\hline & & $\mathrm{C}$ & 1.1057 & $-16.6060 * * *$ & $-7.0143 * * *$ & $-3.5244 * * *$ & 0.5975 & $5.5756 * * *$ & $8.7095^{* * *}$ & $25.259 * * *$ \\
\hline & & $\mathrm{R}_{t-1}$ & 0.0075 & $0.4674 * * *$ & $0.2828^{* * *}$ & 0.0698 & 0.0858 & 0.0406 & 0.0096 & -0.2913 \\
\hline & & CSI- $* \mathrm{C}$ & $-4.7085^{*}$ & $-22.0998^{* * *}$ & $-18.0192^{* * *}$ & $-9.6561^{* *}$ & -0.4909 & 0.5943 & -1.3210 & 3.1844 \\
\hline & & BCS $-{ }^{*} \mathrm{C}$ & $-7.7476^{* * * *}$ & -1.4687 & -0.1549 & -2.7022 & -4.0759 & $-7.9796^{*}$ & -3.6281 & -12.0683 \\
\hline & & FKLI-*C & 2.1990 & 2.0901 & -8.5941 & -4.7435 & -0.5359 & 3.6103 & 0.6621 & 15.0235 \\
\hline & & $R^{2}$ & 0.1024 & 0.3637 & 0.2160 & 0.1307 & 0.0259 & 0.0133 & 0.0158 & 0.2473 \\
\hline
\end{tabular}

Corresponding Author: Jasman Tuyon can be reached at jasma402@sabah.uitm.edu.my 